NBER WORKING PAPER SERIES

A THEORY OF MACROPRUDENTIAL POLICIES IN THE PRESENCE OF NOMINAL RIGIDITIES

Emmanuel Farhi

Iván Werning

Working Paper 19313

http://www.nber.org/papers/w19313

\author{
NATIONAL BUREAU OF ECONOMIC RESEARCH \\ 1050 Massachusetts Avenue \\ Cambridge, MA 02138
}

August 2013

This paper was first circulated under the title "On the Inefficiency of Financial Market Equilibria in Macroeconomic Models with Nominal Rigidities". We thank Fernando Alvarez, Adrien Auclert, Markus Brunnermeier, Gauti Eggertsson, Olivier Jeanne, Guido Lorenzoni, Nobuhiro Kiyotaki, Anton Korinek, John Geanakoplos, Ben Moll, Herakles Polemarchakis, Tomas Sargent, Jean Tirole, Jaume Ventura, for useful comments. We thank seminar and conference participants at various seminars and conferences. Ben Hebert provided outstanding research assistance. The views expressed herein are those of the authors and do not necessarily reflect the views of the National Bureau of Economic Research.

NBER working papers are circulated for discussion and comment purposes. They have not been peerreviewed or been subject to the review by the NBER Board of Directors that accompanies official NBER publications.

(C) 2013 by Emmanuel Farhi and Iván Werning. All rights reserved. Short sections of text, not to exceed two paragraphs, may be quoted without explicit permission provided that full credit, including $(\subset$ notice, is given to the source. 
A Theory of Macroprudential Policies in the Presence of Nominal Rigidities

Emmanuel Farhi and Iván Werning

NBER Working Paper No. 19313

August 2013, Revised May 2015

JEL No. D5,D6,D62,E3,E4,E5,E58

\begin{abstract}
We propose a theory of monetary policy and macroprudential interventions in financial markets. We focus on economies with nominal rigidities in goods and labor markets and subject to constraints on monetary policy, such as the zero lower bound or fixed exchange rates. We identify an aggregate demand externality that can be corrected by macroprudential interventions in financial markets. Ex post, the distribution of wealth across agents affects aggregate demand and output. Ex ante, however, these effects are not internalized in private financial decisions. We provide a simple formula for the required financial interventions that depends on a small number of measurable sufficient statistics. We also characterize optimal monetary policy. We extend our framework to incorporate pecuniary externalities, providing a unified approach to both externalities. Finally, we provide a number of applications which illustrate the relevance of our theory.
\end{abstract}

\author{
Emmanuel Farhi \\ Harvard University \\ Department of Economics \\ Littauer Center \\ Cambridge, MA 02138 \\ and NBER \\ efarhi@harvard.edu \\ Iván Werning \\ Department of Economics, E17-234 \\ MIT \\ 77 Massachusetts Avenue \\ Cambridge, MA 02139 \\ and NBER \\ iwerning@mit.edu
}




\title{
A Theory of Macroprudential Policies in the Presence of Nominal Rigidities*
}

\author{
Emmanuel Farhi \\ Harvard University
}

\author{
Iván Werning \\ MIT
}

June 2015

\begin{abstract}
We propose a theory of monetary policy and macroprudential interventions in financial markets. We focus on economies with nominal rigidities in goods and labor markets and subject to constraints on monetary policy, such as the zero lower bound or fixed exchange rates. We identify an aggregate demand externality that can be corrected by macroprudential interventions in financial markets. Ex post, the distribution of wealth across agents affects aggregate demand and output. Ex ante, however, these effects are not internalized in private financial decisions. We provide a simple formula for the required financial interventions that depends on a small number of measurable sufficient statistics. We also characterize optimal monetary policy. We extend our framework to incorporate pecuniary externalities, providing a unified approach to both externalities. Finally, we provide a number of applications which illustrate the relevance of our theory.
\end{abstract}

\section{Introduction}

During the period known as the Great Moderation, a soft consensus emerged suggesting that macroeconomic stabilization should be handled first and foremost by monetary policy. This consensus has been shattered by the Great Recession. A new set of policies aimed at supplementing monetary policy is gaining traction in policy circles. These so-called macroprudential policies involve interventions in financial markets, in the form of taxes or quantity restrictions. Economists are still searching for a comprehensive theoretical model that encompasses both monetary and macroprudential policies. The goal of this paper is to provide such a framework.

${ }^{*}$ We thank Fernando Alvarez, Adrien Auclert, Markus Brunnermeier, Gauti Eggertsson, Olivier Jeanne, Guido Lorenzoni, Nobuhiro Kiyotaki, Anton Korinek, John Geanakoplos, Ben Moll, Herakles Polemarchakis, Tomas Sargent, Jean Tirole, Jaume Ventura, for useful comments. We thank seminar and conference participants at various seminars and conferences. Ben Hebert provided outstanding research assistance. 
One of the dominant existing theoretical justifications for macroprudential policies is based on pecuniary externalities, which were first shown to arise when a simple friction, market incompleteness, is introduced into the Arrow-Debreu framework (see e.g. Hart, 1975; Stiglitz, 1982; Geanakoplos and Polemarchakis, 1985; Geanakoplos et al., 1990). The logic is as follows. When asset markets are incomplete and there is more than one commodity, a redistribution of asset holdings generically induces relative price changes in spot markets, in each state of the world. These relative price changes, in turn, affect the spanning properties of the limited assets that are available, potentially improving insurance. Such a pecuniary externality is not internalized by private agents. As a result, the equilibrium is generically constrained inefficient: it can be improved upon by interventions in the existing financial markets. Similar results obtain in economies with borrowing constraints that depend on prices of goods and assets, or when contracting is constrained by private information (see e.g. Greenwald and Stiglitz, 1986). A large literature has leveraged these theoretical insights to justify macroprudential interventions. ${ }^{1}$

In this paper, we offer an alternative general theory for macroprudential policies based on a different set of frictions. Indeed, in our baseline model, the only frictions are nominal rigidities and, possibly, constraints on monetary policy such as the zero lower bound or a fixed exchange rate. Instead of pecuniary externalities, our theory emphasizes aggregate demand externalities. In addition to providing a new foundation for macroprudential policies, our framework, focusing on monetary policy and nominal rigidities, is well posed for the joint study of monetary and macroprudential policy.

We provide two sets of results. First, using a perturbation argument similar in spirit to that in Geanakoplos and Polemarchakis (1985), we show that equilibria that are not first best can be improved upon by interventions in financial markets, except in non-generic knife-edged cases. Although we share the focus on constrained inefficiency with the pecuniary externality literature, the source of inefficiency is completely different. ${ }^{2}$ In that literature, the key frictions lie in financial markets themselves; in our baseline model, we assume complete markets. Pecuniary externalities rely on price movements; in our framework price rigidities tend to negate such effects. ${ }^{3}$ Our

\footnotetext{
${ }^{1}$ See e.g. Caballero and Krishnamurthy (2001); Lorenzoni (2008); Farhi et al. (2009); Bianchi and Mendoza (2010); Jeanne and Korinek (2010); Bianchi (2011); Korinek (2011); Davilla (2011); Stein (2012); Korinek (2012a,b); Jeanne and Korinek (2013). Woodford (2011) studies a model with nominal rigidities and pecuniary externalities, and characterizes optimal monetary policy and optimal macroprudential policy. Importantly, and in contrast to our theory, the justification for macroprudential interventions in his model is entirely driven by the presence of pecuniary externalities.

${ }^{2}$ By constrained inefficiency we mean, in both cases, that the planner does not necessarily have the tools necessary to entirely overcome the frictions leading to inefficiencies. For example, in our applications the policy instruments can be interpreted as taxes or regulation on borrowing or portfolio decisions. It is also important that monetary policy be constrained and unable to overcome the nominal rigidities. In some applications it is also important that tax instruments be somewhat constrained, to avoid being able to control all relative prices and effectively undo price rigidities.

${ }^{3}$ Using a disequilibrium approach, Herings and Polemarchakis (2005) show that under some conditions, it is possible to construct fix-price equilibria that Pareto dominate competitive (flex-price) equilibria when asset markets are incomplete in the absence of asset market interventions. In some way, our approach is the polar opposite. It takes price rigidities as a constraint (if prices were flexible, competitive equilibria would be Pareto efficient) and looks
} 
results are instead driven by aggregate demand externalities that arise from the price rigidities.

Second, we jointly characterize optimal monetary and macroprudential policy by providing explicit formulas combining three sufficient statistics: elasticities of substitution, marginal propensities to spend, and good-specific wedges. Wedges are a standard measure for the departure of an allocation from the first best benchmark-a positive wedge signals the under-provision of a good. ${ }^{4}$

Our formulas for optimal monetary policy adapt the standard optimal monetary policy targeting rules derived in the New Keynesian literature (see e.g. Woodford, 2003) to our setting with macroprudential policy. These standard targeting rules form the core of the inflation targeting doctrine and its elaborations. Formally, we express the relevant first-order conditions as a linear system of equations in the wedges, with coefficients given by substitution elasticities, and forcing variables given by the derivatives of the constraints on price adjustment and monetary policy, as well as their associated multipliers. Wedges are nonzero to the extent that these forcing variables are nonzero, indicating that the corresponding constraints are binding. Intuitively, monetary policy targets a set of weighted averages of the wedges. The forcing variables capture the fact that nominal rigidities and constraints on monetary policy prevent achieving these ideal targets.

Our formula for optimal macroprudential policy provides the financial taxes required on any asset and agent in the economy. It depends on simple combination of wedges and marginal propensities to spend. According to the formula, in our baseline model the Arrow-Debreu holdings for an agent in a particular state of the world is relatively subsidized if this agent tends to spends relatively heavily on goods with high wedges. Intuitively, optimal financial taxes provide incentives for agents with higher marginal propensities to spend on goods that are relatively depressed in some states to tilt their wealth towards these states. The resulting change in the ex-post wealth distribution increases aggregate demand for these goods, lowering the wedge and mitigating the inefficiency. These macroeconomic stabilization benefits are due to an aggregate demand externality that is not internalized by atomistic private agents. As a result, optimal government intervention in financial markets can be understood as Pigouvian corrective taxes, or associated quantity restrictions, that overcome this market failure. ${ }^{5}$

We allow a subset of goods to be rationed to capture, in particular, the possibility of underemployment with nominal wage rigidities, where workers are forced off their labor supply curves. Our formula for financial taxes includes only wedges and marginal propensities to spend on those goods that are not rationed. This is natural, since marginal propensities to spend on rationed goods are effectively zero.

for Pareto improvements through interventions in asset markets when markets are complete. Another important difference is that we are concerned with nominal rigidities and constraints on monetary policy, while their approach is real.

${ }^{4}$ Output gaps in log-linearized New Keynesian models are first order approximation of wedges.

${ }^{5}$ Blanchard and Kiyotaki (1987) isolate a different form of aggregate demand externality. In their framework, for a given level of nominal money balances, individual firms' price setting decisions influence aggregate demand through the level of real money balances, an effect which they fail to internalize. 
We also briefly consider ex-post redistribution after the realization of the state of world. In our model, redistributing towards agents with higher marginal propensities to spend on depressed goods provides macroeconomic stabilization benefits. Rather than equalizing private marginal utilities of income, the ex-post optimum equalizes social marginal utilities of income, where for any given agent, the difference between private and social marginal utility of income coincides with the optimal financial tax required in that state of the world. We use this result to argue that the optimum is time consistent: as long as the right set of ex-ante macroprudential policies is available, no commitment over ex-post transfers is required. Financial taxes are required in order to prevent agents from undoing the desired ex-post wealth distribution through financial markets.

Our baseline model purposefully abstracts from financial markets frictions that give rise to pecuniary externalities, such as incomplete markets and borrowing constraints that depend on prices. This allows us to focus on an entirely different set of frictions-nominal rigidities and constraints on monetary policy - that give rise to aggregate demand externalities, providing a distinct rationale for macroprudential policies. However, the two theories are not mutually exclusive and both frictions may be present in some applications. To address this possibility, we extend our baseline model and provide a unified framework that incorporates both aggregate demand and pecuniary externalities. The system of linear equations in wedges describing optimal monetary policy now acquires new forcing variables, due to market incompleteness and the presence of prices in borrowing constraints. Remarkably, however, our formula for optimal macroprudential policy is unchanged in the unified model. To be sure, the presence of pecuniary externalities affects wedges, but does not affect the mapping from wedges to macroprudential policy.

We illustrate our results with four applications, three novel ones and one that appeared earlier in our own work. ${ }^{6}$ All our examples are fit within our general model. Some feature only aggregate demand externalities, while others fit within our feature both aggregate demand and pecuniary externalities. These applications demonstrate the versatility of our framework from a theoretical perspective and the importance of the underlying mechanisms from an applied perspective.

Our first application is motivated by Eggertsson and Krugman (2012) and Guerrieri and Lorenzoni (2011), that show how episodes with household deleveraging can throw the economy into a liquidity trap. There are two types of agents: borrowers and savers. Borrowers are initially indebted to savers, but must pay down their debts. This "deleveraging" requirement amounts to a binding borrowing constraint that reduces equilibrium real interest rates in a flexible price model and may lead to a liquidity-trap recession in the presence of nominal rigidities. We extend this model by adding an earlier period, before the deleveraging shock, where the borrower contracts debt, capturing the "credit boom" phase before the crisis. In parallel and independent

\footnotetext{
${ }^{6}$ In a previous version of this paper, we also presented two additional applications: an application to risk sharing through financial markets or fiscal transfers in currency unions along the lines of Farhi and Werning (2012b), and an application to capital controls with flexible exchange rates in anticipation of a liquidity trap. We have excluded these applications in the current version to economize on space.
} 
work, Korinek and Simsek (2014) analyze a similar situation.

Our main result in this context emphasizes ex-ante macroprudential restrictions on borrowing, which could in practice take the form of regulatory Loan-To-Value (LTV) or Debt-To-Income (DTI) ratios. The optimal intervention lowers the build up in debt during the credit boom. As a result, borrowers are richer, and savers poorer, when the crisis hits. This increases aggregate demand,since borrowers have a higher marginal propensity to consume, stimulating the economy precisely when the economy is depressed. This stabilization benefit is is not internalized by individual borrowers. Optimal policy corrects this an aggregate demand externality by imposing macroprudential Pigouvian taxes, or corresponding quantity restrictions, on borrowing.

There has been considerable recent debate over the proper conduct of monetary policy during a credit boom. Should monetary policy lean against the wind by raising interest rates? Or is it best to continue to focus on the usual macroeconomic targets? Our model sheds light on these questions. We show that in the initial period, during the credit boom, the optimal mix of monetary and macroprudential policy achieves perfect macroeconomic stabilization. There is no need to sacrifice macroeconomic stability by tightening monetary policy to improve financial stability. It is better to tighten macroprudential policy instead.

We present a few extensions of the deleveraging model. We introduce uncertainty, so that the deleveraging requirement on borrowers only occurs with some probability. We use this to show that macroprudential policies during the credit boom only restrict borrowing against future states of nature where the zero-lower bound binds. This highlights that the problem is one of under insurance in borrowing, rather than over borrowing overall.

We also extend the model by adding a housing sector and study borrowing constraints that depend on housing prices. This leads to a hybrid model with both aggregate demand and pecuniary externalities. These two externalities amplify each other through a feedback loop: ex-ante borrowing reduces ex-post aggregate demand, which in turn reduces housing prices and tightens ex-post borrowing constraints further, further reducing ex-post aggregate demand etc. ad infinitum. Optimal macroprudential interventions corrects for both mutually reinforcing externalities.

Our second application concerns Mundell's trilemma, drawing on our previous work in Farhi and Werning (2012a) (see also Schmitt-Grohe and Uribe, 2012). ${ }^{7,8}$ We consider a small open economy that can attain perfect macroeconomic stabilization with flexible exchange rates, just as envisioned by Friedman (1953). However, we consider a case where monetary policy is constrained

\footnotetext{
${ }^{7}$ To avoid overextending ourselves, we stop short of developing and explaining this application in full. We provide a stylized version of the basic model and results that are enough to appreciate the unifying aspects emphasized by the general approach taken in the present paper. However, Farhi and Werning (2012a) address a number of specific issues that arise in the context of this application using a richer model.

${ }^{8}$ In Schmitt-Grohe and Uribe (2012), nominal rigidities take the form of downward sticky nominal wages. Wages can only decrease over time at a certain pace that increases with the amount of slack in the economy, according to an ad hoc norm. Because wages are not set in a forward looking manner in good times, this introduces an additional rationale for macroprudential policy to influence the behavior of wages, taking into account that it will be hard to decrease them later in bad times. This motive, which could account for significant welfare effects, is not captured in our baseline model.
} 
by a fixed exchange rate, due to a hard currency peg or membership in a currency union. With monetary policy constrained in this way, we show that it is optimal to use macroprudential capital controls. This can be understood as a second-best way of regaining monetary policy autonomy, that is, control over the interest rate. Taxes on inflows should be deployed to cool down booms, and taxes on outflows to mitigate recessions.

Our third and fourth applications show a role for capital controls even when the exchange rate is flexible, outlining an important qualification to the Mundellian paradigm that ties the benefits of capital controls to fixed exchange rate regimes. We present two examples without constraints on monetary policy, where the need for macroprudential capital controls arise due to the interaction of financial market imperfections and nominal rigidities. In the third application, domestic agents are subject to a collateral constraints that depend on the terms of trade, a standard assumption in the international literature on "sudden stops", i.e. sharp reversals in capital flows. In the fourth application, there are incomplete markets, with only non-contingent nominal debt denominated in local and foreign currency. These applications feature both aggregate demand and pecuniary externalities. In the third example application, taxes on capital inflows should be imposed preemptively in anticipation of binding collateral constraints. The fourth example application shows that capital controls should differentiate between local- and foreign-currency borrowing, with higher taxes on foreign-currency debt. This is consistent with common wisdom within policy circles arguing that international credit booms fueled by foreign-currency debt are especially problematic.

The rest of the paper is organized as follows. Section 2 introduces the baseline model. Section 3 characterizes ex-ante constrained-efficient Pareto optima, deriving conditions for monetary and macroprudential policy. Section 4 introduces our unified model that allows for both pecuniary and aggregate demand externalities. Section 5 presents four applications. Section 6 concludes.

\section{Model Framework}

This section lays out our baseline framework. The model strikes a balance between generality and tractability: general enough to capture a wide set of applications, but tractable enough to derive our main results in a way that transparently conveys the mechanisms at work. Our baseline model isolates aggregate demand externalities, shutting down pecuniary externalities. Section 4 provides a unified model that incorporates both types of externalities.

\subsection{Environment}

We consider an economy populated by heterogenous agents. Financial markets are assumed to be perfect, except possibly subject to simple borrowing limits. Heterogeneity is important to generate meaningful financial transactions and to allow differences in spending patterns. We abstract 
from incomplete markets or borrowing constraints that depend on prices to avoid pecuniary externalities and isolate the effects of aggregate demand externalities.

In addition to financial markets, agents transact in goods and labor markets that suffer from nominal rigidities. Monetary policy may mitigate the resulting inefficiencies, but we will be most interested in situations where it is unable to fully restore the first best. This may be due to self-imposed constraints on monetary policy such as fixed exchange rates, or more intrinsic constraints, such as the zero lower bound on nominal interest rates. Even when monetary policy is unconstrained it may not be able to achieve the first best, depending on the nature of the shocks and nominal rigidities. ${ }^{9}$

We adopt notation following conventions from the general equilibrium literature. Commodities are indexed by $s \in S$ and $j \in J_{s}$, so that the consumption vector is of dimension $N=\sum_{s \in S} \# J_{s}$. The dichotomy between $s$ and $j$ is required to separate perfect financial markets from imperfect goods and labor markets. In applications, $s \in S$ denotes a state of the world, a time period, or a set of time periods, while $j \in J_{s}$ denotes commodities within state $s$. An important distinction between $s \in S$ and $j \in J_{s}$ is that we allow the government to use taxes or quantity restrictions to influence financial transactions across states, but rule out such policy tools to influence spot transactions within a state. This is done to focus on the role of macroprudential policy interventions in financial markets.

Technology is described by

$$
F\left(\left\{Y_{j, s}\right\}\right) \leq 0,
$$

where $Y_{j, s}$ is the production of good $j$ in state $s$ and $F: \mathbb{R}^{N} \rightarrow \mathbb{R}$ is a convex function.

Agent $i \in I$ has preferences described by the utility function

$$
\sum_{s \in S} U^{i}\left(\left\{X_{j, s}^{i}\right\} ; s\right),
$$

where the functions $U^{i}(\cdot ; s)$ are concave and $X_{j, s}^{i}$ is the consumption of agent $i$ of good $j$ in state $s$. The state-dependent utility function $U^{i}(\cdot ; s)$ may be embed probabilities of states and even allow for heterogenous subjective beliefs across agents.

Agent $i$ faces the budget constraints

$$
\begin{gathered}
\sum_{s \in S} D_{s}^{i} Q_{s}\left(1-\tau_{D, s}^{i}\right) \leq-T^{i}, \\
\sum_{j \in J_{s}} P_{j, s} X_{j, s}^{i} \leq-\hat{T}_{s}^{i}+D_{s}^{i} \quad \forall s \in S,
\end{gathered}
$$

\footnotetext{
${ }^{9}$ In simple closed-economy, one-sector New Keynesian model with sticky prices and flexible wages the "divine coincidence" result provides conditions under which unconstrained monetary policy attains the first best. These results are not immediately applicable in richer frameworks, such as open economies, or multi-sectors models or models that also include nominal wage rigidities. In these situations, the first best would require the adjustment of various relative prices, which are impeded by nominal rigidities that cannot be fully overcome by monetary policy.
} 
where

$$
\hat{T}_{s}^{i}=T_{s}^{i}-x^{i} \sum_{j \in J_{s}} P_{j, s} Y_{j, s}
$$

The first constraint represents the financial market stage, where the agent can transfer wealth across states $s \in S$ by trading in a complete set of Arrow-Debreu securities, where $D_{s}^{i}$ denotes the holdings by agent $i$ of a state-contingent claim that pays one in units of the numeraire in state $s$ and zero in other states and $Q_{s}$ is the price of a unit of this claim. Importantly, we introduce an agentand asset-specific tax/subsidy $\tau_{D, s}^{i}$ so that agents face different net-of-tax/subsidy state prices $Q_{s}\left(1-\tau_{D, s}^{i}\right)$. Note that we could either have $\tau_{D, s}^{i} \geq 0$, corresponding to a subsidy, or $\tau_{D, s}^{i} \leq 0$, corresponding to a tax. In the rest of the paper, we simply refer to $\tau_{D, s}^{i}$ as financial tax, or as a macrorpudential intervention. In addition to this distortion, we also allow for a lump-sum tax $T^{i}$.

The second budget constraint represents the spot market stage. On the right-hand side income $I_{s}^{i}$ is financial wealth $D_{s}^{i}$ net of a lump-sum tax $T_{s}^{i}$ gross of share of profits $x^{i} \sum P_{j, s} Y_{j, s}{ }^{10}$ We allow a lump-sum tax at this stage for convenience. ${ }^{11}$ When labor is one of the commodities in $J_{s}$, labor income is included implicitly on the left-hand side as a negative entry.

It is sometimes useful to allow for a restriction on consumption by imposing

$$
B_{s}^{i}\left(\left\{X_{j, s}^{i}\right\}\right) \leq 0 \quad \forall s \in S, \forall i \in I,
$$

for some convex function $B_{s}^{i}$. Restrictions on the consumption possibility set fit in with standard consumer demand theory. In our applications, this constraint allows us to capture simple borrowing limits. This can be done by labeling consumption (and labor) over two periods as different commodities $j$ under the same state $s$. The constraints do not depend on prices to avoid introducing pecuniary externalities. Section 4 introduces more general borrowing constraints that include prices, giving rise to pecuniary externalities. Importantly, the functions $B_{s}^{i}$ are independent of policy, so that the constraints cannot be directly manipulated by the planner to influence agents' spending decisions within a state.

The indirect utility function for agent $i$ in state $s$ is

$$
V_{s}^{i}\left(I_{s}^{i},\left\{P_{j, s}\right\}\right) \equiv \max _{\left\{X_{j, s}^{i}\right\}} U^{i}\left(\left\{X_{j, s}^{i}\right\} ; s\right) \quad \text { subject to } \quad \sum_{j \in J_{s}} P_{j, s} X_{j, s}^{i} \leq I_{s}^{i} \quad \text { and } \quad B_{s}^{i}\left(\left\{X_{j, s}^{i}\right\}\right) \leq 0 \text {. }
$$

Let

$$
X_{j, s}^{i}=X_{j, s}^{i}\left(I_{s}^{i}\left\{P_{j, s}\right\}\right)
$$

denote the associated Marshallian demand functions and by $S_{k, j, s}^{i}=X_{P_{k}, j, s}^{i}+X_{k, s}^{i} X_{I, j, s}^{i}$ the associated Slutsky matrix. Note that when one of the commodities $j \in J_{S}$ is labor, this problem assumes that agents are free to choose their labor supply, given the wage, i.e. they are always on their

\footnotetext{
${ }^{10}$ Here $x^{i}$ denotes the share of profits of agent $i$, with $\sum_{i \in I} x^{i}=1$.

${ }^{11}$ Given complete markets, this lump sum tax is redundant to the planner.
} 
"labor supply curve". Section 3.3 considers situations with sticky wages and rationed labor.

To capture price rigidities and restrictions on monetary policy we impose

$$
\Gamma\left(\left\{P_{j, s}\right\}\right) \leq 0
$$

where $\Gamma: \mathbb{R}^{N} \rightarrow \mathbb{R}^{M}$ is a vector function. This allows us to capture fairly flexible forms of nominal rigidities and constraints on monetary policy, such as the zero lower bound or fixed exchange rates. Section 5 provides concrete applications where these constraints are explicitly spelled out and mapped into the present framework.

On the supply side, we have described technology but postpone a precise description of market structure. Following the seminal analysis of Diamond and Mirrlees (1971) we proceed as if production and prices were controlled by the planner. ${ }^{12}$ Section 5 provides explicit decentralizations for production and price decisions that adopt the standard New Keynesian model with monopolistically competitive firms that post prices and meet demand at these prices. Our planner can implicitly control production and price decisions by appropriate taxes and subsidies. In particular, as is standard in the New Keynesian literature, these taxes are used to remove the distortion from monopoly markups.

The government budget constraints are

$$
\begin{gathered}
\sum_{s \in S} D_{s}^{g} Q_{s}+\sum_{i \in I} \sum_{s \in S} \tau_{D, s}^{i} D_{s}^{i} Q_{s}=\sum_{i \in I} T^{i}, \\
\sum_{j \in J_{s}} P_{j, s} Y_{j, s}+\sum_{i \in I} \hat{T}_{s}^{i}+D_{s}^{g}=0 \quad \forall s \in S .
\end{gathered}
$$

\subsection{Equilibrium}

An equilibrium is an allocation for consumption $\left\{X_{j, s}^{i}\right\}$, output $\left\{Y_{j, s}\right\}$, state contingent debt $\left\{D_{s}^{i}, D_{s}^{g}\right\}$ as well as prices $\left\{Q_{s}\right\}$ and $\left\{P_{j, s}\right\}$, and taxes $\left\{\tau_{D, s}^{i}\right\},\left\{T^{i}\right\}$ and $\left\{T_{s}^{i}\right\}$ such that agents optimize, prices satisfy the nominal rigidity restrictions, the government balances its budget and markets clear so that

$$
Y_{j, s}=\sum_{i \in I} X_{j, s}^{i} \quad \forall s \in S, \forall j \in J_{s}
$$

\footnotetext{
${ }^{12}$ The goal in Diamond and Mirrlees (1971) was to characterize arrangements where agents interact in decentralized markets and the government seeks to achieve some redistributive objective or to raise some revenues. They were led to a second best problem because they assumed that the government could only use a restricted set of instruments, linear commodity taxes. They ruled out lump-sum taxes which would allow the government to achieve its objectives without imposing any distortion, thereby reaching the first best. We are interested in a different set of constraints, namely nominal rigidities in the prices faced by consumers. We also incorporate restrictions on instruments, but of a different nature. In particular, we allow for lump-sum taxes $\left(T^{i}\right.$ and $\left.T_{s}^{i}\right)$, but rule out a complete set of commodity taxes that would allow the government to get around the nominal rigidities and attain the first best.
} 
This implies that the markets for state-contingent claims clear so that

$$
D_{s}^{g}+\sum_{i \in I} D_{s}^{i}=0 \quad \forall s \in S
$$

Proposition 1 (Implementability). An allocation for consumption $\left\{X_{j, s}^{i}\right\}$ and output $\left\{Y_{j, s}\right\}$ together with prices $\left\{P_{j, s}\right\}$ form part of an equilibrium if and only if there are incomes $\left\{I_{s}^{i}\right\}$ such that (1), (2), (3) and (4) hold.

For any feasible allocation, it will be useful to define the wedges $\tau_{j, s}$ :

$$
1-\tau_{j, s}=\frac{P_{j^{*}(s), s}}{P_{j, s}} \frac{F_{j, s}}{F_{j^{*}(s), s}}
$$

for each $s \in S$ given some reference good $j^{*}(s) \in J_{s}$. These wedges are zero at first best allocations. More generally, goods with positive wedges $\tau_{j, s}>0$ feature a deficit of demand (good $j$ is depressed) while goods with negative wedges $\tau_{j, s}<0$ feature an excess of demand (good $j$ is overheated). For example, suppose there is a single consumption good produced from labor, then taking the consumption good as the reference good $j^{*}(s)$, and indexing labor by $j$, the wedge $\tau_{j, s}$ is simply the labor wedge metric defined and measured in the business cycle and search literature. In log-linearized New Keynesian models the labor wedge is negatively related one-for-one to the output gap, a concept defined as the log deviation of output from its efficient level.

\subsection{Planning Problem}

We now formulate the Ramsey planning problem of choosing the equilibrium that maximizes social welfare, computed as a weighted average of agents utilities with Pareto weights $\lambda^{i}$ :

$$
\max \sum_{i \in I} \sum_{s \in S} \lambda^{i} V_{s}^{i}\left(I_{s}^{i}\left\{P_{j, s}\right\}\right)
$$

subject to

$$
\begin{gathered}
F\left(\left\{\sum_{i \in I} X_{j, s}^{i}\left(I_{s}^{i},\left\{P_{j, s}\right\}\right)\right\}\right) \leq 0, \\
\Gamma\left(\left\{P_{j, s}\right\}\right) \leq 0 .
\end{gathered}
$$

\section{Optimal Monetary and Macroprudential Policy}

In this Section we characterize optimal monetary and macroprudential policy as the solution to the planning problem (5). Our main result is a simple formula for optimal interventions, expressed in terms of sufficient statistics. We prove that macroprudential policies are needed except 
in knife-edge cases. We also extend our results to situations with sticky wages. Finally, we compare ex-ante macroprudential policies with ex-post redistribution policies and shed light on the time-consistency properties of optimal policy.

\subsection{Optimal Policy}

The first-order conditions for income $I_{s}^{i}$ and prices $P_{k . s}$ are

$$
\begin{gathered}
\lambda^{i} V_{I, s}^{i}=\mu \sum_{j \in J_{s}} F_{j, s} X_{I, j, s}^{i} \quad \forall i \in I, \forall s \in S, \\
\sum_{i \in I} \lambda^{i} V_{P_{k}, s}^{i}=\sum_{i \in I} \sum_{j \in J_{s}} \mu F_{j, s} X_{P_{k}, j, s}^{i}+v \cdot \Gamma_{P_{k, s}} \quad \forall s \in S, \forall k \in J_{s},
\end{gathered}
$$

where $\mu$ is the multiplier on the resource constraint and $v$ is the vector multiplier on the price constraint. We can rearrange these first-order conditions to derive the following two key equations in terms of wedges

$$
\begin{gathered}
\frac{\lambda^{i} V_{I, s}^{i}}{1-\sum_{j \in J_{s}} P_{j, s} X_{I, j, s}^{i} \tau_{j, s}}=\frac{\mu F_{j^{*}(s), s}}{P_{j^{*}(s), s}} \quad \forall i \in I, \forall s \in S, \\
\frac{\mu F_{j^{*}(s), s}}{P_{j^{*}(s), s}} \sum_{i \in I} \sum_{j \in J_{s}} P_{j, s} \tau_{j, s} S_{k, j, s}^{i}=v \cdot \Gamma_{P_{k, s}} \quad \forall s \in S, \forall k \in J_{s} .
\end{gathered}
$$

The left-hand side of equation (6) defines the correct notion of social marginal utility of income and can be compared to the private marginal utility of income $\lambda^{i} V_{I, s}^{i}$. The difference between the social and private marginal utility of income for of agent $i$ is larger when this agent displays a higher marginal propensity to spend $P_{j, s} X_{I, j, s}^{i}$ with large wedges $\tau_{j, s}$ (depressed goods). Since the right-hand side of equation (6) is independent of $i$, the social marginal utility of income must be equalized across agents in all states of the world $s \in S$.

Equation (6) characterizes optimal macroprudential policy, while equation (7) characterizes optimal monetary policy. Equation (7) expresses optimal monetary policy in terms of policy targets (see e.g. Woodford, 2003) that form a linear system of equations in the wedges $\tau_{j, s}$, with coefficients commensurate with substitution elasticities $S_{k, j, s}^{i}$ and with forcing variables given by the derivatives $\Gamma_{P_{k, s}}$ of the constraints on price adjustment and monetary policy and their associated multipliers $v$. The wedges $\tau_{j, s}$ are non-zero to the extent that these forcing variables are non-zero, indicating that the corresponding constraints are binding. Intuitively, these conditions show that optimal monetary policy targets some weighted average of wedges in each state of the world. If prices $P_{j, s}$ were perfectly free, so that $\Gamma$ is trivial, then it would be possible to achieve $\tau_{j, s}=0$ for all $j \in J$ and $s \in S$. Constraints on price adjustment and monetary policy can prevent achieving the ideal outcome, with zero wedges. ${ }^{13}$

\footnotetext{
${ }^{13}$ The model can be generalized to the case where the constraint on prices and monetary policy depends directly on the output vector $\left\{Y_{j, s}\right\}$, so that it becomes $\Gamma\left(\left\{P_{j, s}\right\},\left\{Y_{j, s}\right\}\right) \leq 0$. This would be the case for example with a
} 
Turning back to equation (6), nonzero wedges and marginal propensities to spend feed into social marginal utilities of income. These can be used to compute the optimal financial taxes $\tau_{D, s}^{i}$ required to implement the social optimum. ${ }^{14}$

Proposition 2. The solution to the planning problem (5) can be implemented with financial taxes given by

$$
\tau_{D, s}^{i}=\sum_{j \in J_{s}} P_{j, s} X_{I, j, s}^{i} \tau_{j, s}
$$

with wedges $\tau_{j, s}$ satisfying the weighted average conditions (7).

Private financial decisions are based on private marginal utilities instead of social marginal utilities. Corrective taxes are required to align private and social incentives. The difference between private and social marginal arises from an aggregate demand externality. Intuitively, financial decisions determine the wealth distribution across states $s \in S$. When agents have different spending patterns, changes in the distribution of wealth affect demand. These changes in demand can improve efficiency, but infinitesimal agents do not internalize the macroeconomic consequences of their financial decisions. Aggregate demand externalities justify government interventions.

Our formula shows that the taxes $\tau_{D, s}^{i}$ can be expressed in terms of two sufficient statistics: the marginal propensities to spend $P_{j, s} X_{I, j, s}^{i}$ and wedges $\tau_{j, s}$. Both of these variables are well-known concepts, that can in principle be measured from the data or calibrated from standard models, and are the focus of large applied literatures. According to the formula, financial taxes should encourage an agent to shift wealth towards a state if this agent tends to spend relatively more (at the margin) than others on goods with positive wedges.

To be specific, Proposition 2 delivers the tax rates required when state prices $Q_{s}$ are proportional to $F_{j^{*}(s), s} / P_{j^{*}(s), s}$. There are other possibilities since all that matters for consumers is the after tax prices $\left(1-\tau_{D, s}^{i}\right) Q_{s}$. However, the relative financial taxes $\left(1-\tau_{D, s}^{i}\right) /\left(1-\tau_{D, s}^{i^{\prime}}\right)$ faced by two agents $i$ and $i^{\prime}$ in any given state $s \in S$ are uniquely determined by $\left(1-\sum_{j \in J_{s}} P_{j, s} X_{I, j, s}^{i} \tau_{j, s}\right) /(1-$ $\left.\sum_{j \in J_{s}} P_{j, s} X_{I, j, s}^{i^{\prime}} \tau_{j, s}\right)$. With nonzero wedges $\tau_{j, s}$ and differences in marginal propensities to spend $P_{j, s} X_{I, j, s}^{i}$ across agents $i$ and $i^{\prime}$, relative financial taxes are nonzero in general. We formalize this statement in Section 3.2, establishing that nonzero financial taxes are generically required.

A standard Ricardian equivalence indeterminacy permeates our implementation: any ex-post wealth distribution can be obtained by different combinations of financial portfolios $D_{s}^{i}$ and lump-

Keynesian Philips curve. Both our formulas, for optimal monetary and macroprudential policy, go through with one modification: $\tau_{j, s}$ is replaced everywhere by $\tau_{j, s}-\frac{1}{P_{j, s}} \frac{P_{j^{*}(s), s}}{\mu F_{j^{*}(s), s}}\left(v \cdot \Gamma_{Y_{j, s}}\right)$. In other words, what matters now is not solely whether a good is depressed, as captured by $\tau_{j, s}$, but whether increasing spending on this good relaxes the constraint on prices and monetary policy, as reflected in the new term $-\frac{1}{P_{j, s}} \frac{P_{j^{*}}(s), s}{\mu F_{j^{*}}(s), s}\left(v \cdot \Gamma_{Y_{j, s}}\right)$.

${ }^{14}$ Proposition 2 shows that constrained Pareto efficient outcomes-solutions of the planning problem (5) for some set of Pareto weights $\left\{\lambda^{i}\right\}$ —can be implemented with taxes on state contingent debt. There are of course equivalent implementations with quantity restrictions (caps and floors on portfolio holdings) instead of taxes, and we use both in our applications, depending on the specific context. Our theory is silent on the relative desirability of these two forms of intervention. 
sum taxes $T_{s}^{i}$. Loosely speaking, any insurance can be achieved privately through financial markets or through the government. Importantly, identical financial taxes $\tau_{D, s}^{i}$ are required in both cases. In the first case, the taxes are required to induce agents to purchase the right amount of insurance. In the second case, to prevent agents from undoing the government-provided insurance.

Arbitrary securities. Our model features complete markets with Arrow-Debreu securities. We can easily allow for an arbitrary security $a$ in zero net supply with payoff $Z_{a, s}$ in each state $s \in S$ to be traded. The analysis is identical (the resulting planning problem is the same). And the optimal financial tax on security $a$ is given by a simple formula which can be easily deduced from Proposition 2.

Corollary. If security a were independently traded, then the solution to planning problem the planning problem (5) would require an agent specific financial tax on security a given by

$$
\tau_{a}^{i}=\sum_{s \in S} \frac{\frac{F_{j^{*}(s), s}}{P_{j^{*}(s), s}} Z_{a, s}}{\sum_{s \in S} \frac{F_{j^{*}(s), s}}{P_{j^{*}(s), s}} Z_{a, s}} \tau_{D, s}^{i} .
$$

Security $a$ can be replicated by a portfolio consisting of $Z_{a, s}$ units of every Arrow-Debreu security paying one in state $s \in S$. For each agent $i$, the optimal tax financial $\tau_{a}^{i}$ on security $a$ is a weighted average of the underlying Arrow-Debreu securities with weights commensurate with their proportions $Z_{a, s}$ in the replicating portfolio and state prices $Q_{s}=F_{j^{*}(s), s} / P_{j^{*}(s), s}$.

Policy instruments. We have allowed for a rich set of policy instruments in the form of monetary policy, a complete set of financial taxes $\left\{\tau_{D, s}^{i}\right\}$, and a complete set of lump-sum taxes $\left\{T^{i}\right\}$ and $\left\{T_{s}^{i}\right\}$. These instruments allow the implementation of a large set of allocations characterized in Proposition 1. The complete set of financial taxes $\left\{\tau_{D, s}^{i}\right\}$ allows the planner to control the portfolio decisions of each agent. This complete set of financial taxes is the same as that considered in the pecuniary externalities literature. The complete set of lump-sum taxes $\left\{T^{i}\right\}$ and $\left\{T_{s}^{i}\right\}$ ensure that the sole objective of financial taxes is to correct for the resulting market failure, and not to indirectly redistribute resources across agents (recall that the lump-sum taxes $\left\{T_{s}^{i}\right\}$ are actually redundant). Similar lump-sum taxes are considered in the pecuniary externalities literature, and for the same reason. Hence, and in the same spirit as the pecuniary externalities literature, the set of policy instruments that we consider is theoretically compelling because it allows to neatly zoom in on a key macroecomomic externality, in our case an aggregate demand externality.

But a natural question is whether such a rich array of agent-specific taxes is likely to be available in practice. In our applications, there is a limited amount of heterogeneity across agents which come in two types: borrowers and savers, or domestics and foreigners. In these settings, the set of policy instruments that are needed to implement constrained efficient allocations is relatively limited: simple Loan-To-Value ratio restrictions or capital controls are enough. The de- 
mands on the set of policy instruments increase in environments with richer heterogeneity. It is sometimes possible to construct alternative implementations where all agents are confronted with the same nonlinear financial tax schedule as a function of portfolios, but face different agentspecific marginal financial taxes because they endogenously choose different portfolios. ${ }^{15}$ Finally, it may be of interest to impose additional exogenous restrictions on the set of available financial taxes. We conjecture that some averaged-out version of our results would obtain, but characterizing optimal policy in this context goes beyond the scope of this paper, and we leave it for future research.

One could also consider going in the opposite direction by allowing for a richer, rather than more restricted, set of policy instruments. In particular, it is well understood that if rich and flexible enough commodity taxes are available, and in particular a full set of taxes that change consumer prices for given sticky producer prices, then it is possible to completely circumvent nominal rigidities and implement the first best, independently of constraints on monetary policy (see e.g. Correia et al., 2008, 2013; Farhi et al., 2014). These commodity taxes can clearly be useful, but it is difficult to imagine that they would be flexible enough in practice to actually deliver the first best. While we do not elaborate on this point, our model allows us to capture these taxes as well as constraints on their use. Nominal rigidities, constraints on monetary policy, and constraints on such commodity taxes are all captured by the constraint $\Gamma\left(\left\{P_{j, s}\right\}\right) \leq 0$ as a function of consumer prices $\left\{P_{j, s}\right\}$.

\subsection{On the Generic Need for Macroprudential Interventions}

A constrained efficient allocation can be implemented without financial taxes only if

$$
\frac{1-\sum_{j \in J_{s}} P_{j, s} X_{I, j, s}^{i} \tau_{j, s}}{1-\sum_{j \in J_{s}} P_{j, s} X_{I, j, s}^{i^{\prime}} \tau_{j, s}}=\frac{1-\sum_{j \in J_{s^{\prime}}} P_{j, s^{\prime}} X_{I, j, s^{\prime}}^{i} \tau_{j, s^{\prime}}}{1-\sum_{j \in J_{s^{\prime}}} P_{j, s^{\prime}} X_{I, j, s^{\prime}}^{i^{\prime}} \tau_{j, s^{\prime}}} \quad \forall i \in I, i^{\prime} \in I, s \in S, s^{\prime} \in S .
$$

Proposition 3 below establishes that this only happens in knife-edge cases, that is, in situations that are not generic.

To establish this result we consider a utility perturbation described by a set of utility functions $U^{i, \epsilon}$ indexed by $\epsilon>0$. We restrict attention to perturbations where the functions $U^{i, \epsilon}(\cdot ; s)$, their derivatives $D U^{i, \epsilon}(\cdot ; s)$ and their second second derivatives $D^{2} U^{i, \epsilon}(\cdot ; s)$ converge uniformly on compact sets as $\epsilon \rightarrow 0$ to $D U^{i}(\cdot ; s)$ and $D^{2} U^{i}(\cdot ; s)$, respectively. Our next result presumes a constrained efficient allocation that is not first best, so that $\tau_{j, s} \neq 0$ for some $s \in S$ and $j \in J_{s}$. We then show that if this allocation can be implemented without financial taxes, so that (8) holds, we can then find a utility perturbation for which the optimum requires financial taxes. That is, for

\footnotetext{
${ }^{15}$ For example, in our first application in Section 5.1, we use a constraint on borrowing as a policy instrument, which is a form of nonlinear financial tax on borrowing. An endogenous outcome of the model is that this policyinduced borrowing constraint affects only borrowers but not savers. As a result, borrowers face a higher implicit marginal tax rate on borrowing than savers.
} 
which (8) is violated.

Proposition 3. Suppose that the solution of the planning problem (5) can be implemented without financial taxes. Suppose in addition that it is not first best. Then we can find a utility perturbation $U^{i, \epsilon}$ such that for $\epsilon>0$ small enough, the solution of the perturbed planning problem where $U^{i}$ is replaced by $U^{i, \epsilon}$ cannot be implemented without financial taxes.

The basic idea of the proof is as follows. Denote the incomes and prices that solve the nonperturbed planning problem by $\bar{I}_{s}^{i}$ and $\bar{P}_{j, s}$, and we denote place a bar over variables representing functions evaluated at these income and prices. We construct a utility perturbation $U^{i, \epsilon}$ such that at the incomes $\bar{I}_{S}^{i}$ and prices $\bar{P}_{S}$, the individual demand functions $\bar{X}_{S}^{i, \epsilon}$ are unchanged, the Slutsky matrices $\bar{S}_{s}^{i, \epsilon}$ are unchanged, the social marginal utility of incomes $\lambda^{i} \bar{V}_{I, s}^{i, \epsilon} /\left(1-\sum_{j \in J_{s}} \bar{P}_{j, s} \bar{X}_{I, j, s}^{i, \epsilon} \bar{\tau}_{j, s}\right)$ are unchanged, but the income derivatives of the individual demand functions $\bar{X}_{I, j, s}^{i, \epsilon}$ are changed in such a way that (8) is now violated. Taken together, these conditions guarantee the incomes $\bar{I}_{s}^{i}$ and prices $\bar{P}_{j, s}$ still solve the planning problem with the perturbed utility functions. Indeed, at these incomes and prices, and with the perturbed utility functions, the constraints are still verified (because the quantities demanded are unchanged), and so are the first order conditions for optimality because the Slutsky matrices and the social marginal utilities of income are unchanged. However, given that (8) is violated, the solution cannot be implemented without financial taxes.

The requirement that the allocation not be first best is important. For example, so that there are no restrictions on prices, i.e. $\Gamma$ is simply the zero function. In this case, constrained efficient allocations are always first best, and can always be implemented without financial taxes. The proof outlined above then fails since all the wedges $\bar{\tau}_{j, s}$ are zero, making it impossible to change income derivatives of individual demand functions $\bar{X}_{I, j, s}^{i, \epsilon}$ to create a violation in (8).

Now suppose that the solution of the planning problem (5) requires financial taxes-i.e. (5) is violated. Then by continuity, all utility perturbations $U^{i, \epsilon}$ are such that for $\epsilon>0$ small enough, the solution of the perturbed planning problem where where $U^{i}$ is replaced by $U^{i, \epsilon}$ cannot be implemented without financial taxes-i.e. (5) is violated. Together with Proposition 3, this indicates that constrained efficient allocations that are not first best cannot generically be implemented without financial taxes.

\subsection{Rationing and Sticky Wages}

So far our model accommodates nominal price rigidities, but not nominal wage rigidities. In the model, agents are choosing quantities of goods subject to prices, that is, they are on their demand curves. In particular, if good $j \in J_{s}$ represents leisure, this implies that agents are choosing labor, that is, they are on their labor supply curve (leisure demand curve).

We now extend the model to allow for sticky wages. Indeed, we proceed in a slightly more general manner and consider various forms of rationing applying to different goods, with sticky wages and rationing in labor markets emerging as one application. 
General model with rationing. In each state $s$, there exists a subset $\bar{J}_{s} \subseteq J_{s}$ of goods for which agents do not get to choose their consumption. The consumption of these goods is given by $\bar{X}_{j, s}^{i}$ exogenously to the agent, but determined endogenously by a rationing mechanism. Quantities $\bar{X}_{j, s}^{i}$ are subject to some constraints $\Theta\left(\left\{\bar{X}_{j, s}^{i}\right\}\right) \leq 0$. For example, efficient rationing corresponds to the case where there are no constraints. Equal rationing corresponds to the case where the constraint imposes that $\bar{X}_{j, s}^{i}=\bar{X}_{j, s}^{i^{\prime}}$ for all $i, i^{\prime} \in I$.

The indirect utility function is now

$$
V_{s}^{i}\left(I_{s}^{i}\left\{P_{j, s}\right\} ;\left\{\bar{X}_{j, s}^{i}\right\}\right)=\max U^{i}\left(\left\{X_{j, s}^{i}\right\} ; s\right)
$$

subject to

$$
\begin{gathered}
\sum_{j \in J_{s}} P_{j, s} X_{j, s}^{i} \leq I_{s^{\prime}}^{i} \\
B_{s}^{i}\left(\left\{X_{j, s}^{i}\right\}\right) \leq 0, \\
X_{j, s}^{i}=\bar{X}_{j, s}^{i} \quad \forall j \in \bar{J}_{s} .
\end{gathered}
$$

As before, we denote by $X_{j, s}^{i}\left(I_{s}^{i},\left\{P_{j, s}\right\} ;\left\{\bar{X}_{j, s}^{i}\right\}\right)$ the associated Marshallian demand functions and by $S_{k, j, s}^{i}=X_{P_{k}, j, s}^{i}+X_{k, s}^{i} X_{I, j, s}^{i}$ the associated Slutsky matrix.

Planning problem. We are led to the planning problem

$$
\max \sum_{i \in I} \sum_{s \in S} \lambda^{i} V_{S}^{i}\left(I_{S}^{i},\left\{P_{j, s}\right\} ;\left\{\bar{X}_{j, s}^{i}\right\}\right),
$$

subject to

$$
\begin{gathered}
F\left(\left\{\sum_{i \in I} X_{j, s}^{i}\left(I_{s}^{i},\left\{P_{j, s}\right\} ;\left\{\bar{X}_{j, s}^{i}\right\}\right)\right\}\right) \leq 0 \\
\Gamma\left(\left\{P_{j, s}\right\}\right) \leq 0 \\
\Theta\left(\left\{\bar{X}_{j, s}^{i}\right\}\right) \leq 0
\end{gathered}
$$

Optimal policy. For each $s \in S$ pick a reference good $j^{*}(s)$ in $J_{s} \backslash \bar{J}_{s}$. Let $\mu$ be the multiplier on the resource constraint, $v$ the multiplier on the price constrain, and $\chi$ the multiplier on the rationing constraint. We obtain the first-order conditions

$$
\begin{gathered}
\frac{\lambda^{i} V_{I, s}^{i}}{1-\sum_{j \in J_{s} \backslash \bar{J}_{s}} P_{j, s} X_{I, j, s}^{i} \tau_{j, s}}=\frac{\mu F_{j^{*}(s), s}}{P_{j^{*}(s), s}} \quad \forall i \in I, \forall s \in S, \\
\frac{\mu F_{j^{*}(s), s}}{P_{j^{*}(s), s}} \sum_{i \in I} \sum_{j \in J_{s} \backslash \bar{J}_{s}} P_{j, s} \tau_{j, s} S_{k, j, s}^{i}=v \cdot \Gamma_{P_{k, s}} \quad \forall s \in S, k \in J_{s} .
\end{gathered}
$$




$$
\lambda^{i} \frac{\partial V_{s}^{i}}{\partial \bar{X}_{k, s}^{i}}=\mu \sum_{j \in J_{s}} F_{j, s} \frac{\partial X_{j, s}^{i}}{\partial \bar{X}_{k, s}^{i}}+\chi \cdot \Theta_{\bar{X}_{k, s}^{i}} \quad \forall s \in S, k \in \bar{J}_{s} .
$$

Proposition 4. The solution to the planning problem (9) can be implemented with taxes given by

$$
\tau_{D, s}^{i}=\sum_{j \in J_{s} \backslash \bar{J}_{s}} P_{j, s} X_{I, j, s}^{i} \tau_{j, s}
$$

where the wedges $\tau_{j, s}$ must satisfy the weighted average conditions (11).

The key difference with the formula in Proposition 2 is that only the goods that are chosen (instead of rationed) appear in the formula. This is natural as for a given agent, wealth in a particular state only influences spending on these goods.

\subsection{Time Consistency and Redistribution}

Our analysis has focused on influencing financial decisions before the realization of the state of the world. From this ex-ante perspective, macroprudential interventions lead to Pareto improvements in expected utility. The key mechanism is that the distribution of wealth $I_{s}^{i}$ across agents in each state $s$ affects demand and, hence, economic activity ex post. However, the presence of both ex-ante and ex-post instruments (ex-ante portfolio taxes and ex-post lump-sum taxes) naturally raises the question of time consistency to which we now turn.

In contrast to our previous analysis, assume that policies are decided sequentially, without commitment. To simplify, let $F$ and $\Gamma$ be separable across states, so that we can write the corresponding constraints as $F_{s}\left(\left\{Y_{j, s}\right\}_{j \in J_{s}}\right) \leq 0$ and $\Gamma_{s}\left(\left\{P_{j, s}\right\}_{j \in J_{s}}\right) \leq 0$ for all $s \in S$. Consider a policy game with two stages, ex ante and ex post. To preserve the idea that agents act as price takers, we proceed as in Chari and Kehoe (1990): we replace agent $i$ by a unit-mass continuum indexed by $h_{i}$ of identical agents of type $i$, where $h_{i}$ is uniformly distributed in $[0,1]$; and we consider anonymous symmetric perfect Bayesian equilibria of the associated game.

In the ex-ante stage, the government chooses financial taxes $\left\{\tau_{D}^{i, s}\right\}$, lump-sum taxes $\left\{T^{i}\right\}$, state prices $\left\{Q_{s}\right\}$, and government portfolio $\left\{D_{s}^{g}\right\}$. Agents choose their portfolios $\left\{D_{s}^{h_{i}}\right\}$. In the ex-post stage, the state $s$ is realized and the government chooses prices $\left\{P_{j, s}\right\}$, and lump-sum taxes $\left\{T_{s}^{i}\right\}$. Agents choose their consumptions $\left\{X_{j, s}^{h_{i}}\right\}$ of the different goods available in state s. Importantly, note that financial taxes $\left\{\tau_{D}^{i, s}\right\}$ and lump-sum taxes $\left\{T^{i}\right\}$ and $\left\{T_{s}^{i}\right\}$ depend only on the agent type $i$ and not on the agent identity $h_{i}$.

The payoff of agent $h_{i}$ of type $i$ at the ex-ante (respectively ex-post) stage is $\sum_{s \in S} U^{i}\left(\left\{X_{j, s}^{h_{i}}\right\} ; s\right)$ (respectively $\left.U^{i}\left(\left\{X_{j, s}^{h_{i}}\right\} ; s\right)\right)$ if his budget constraints are verified; it is $-\infty$ otherwise. The payoff of the government is the weighed average of agents' utilities with weight $\lambda_{i} d h_{i}$ on the utility of a mass $d h_{i}$ of agents of type $i$ if the government budget constraints, the markets for state-contingent claims, the the goods markets all clear, and if in addition $\Gamma_{s}\left(\left\{P_{j, s}\right\}_{j \in J_{s}}\right) \leq 0$ for all $s \in S$; it is $-\infty$ otherwise. 
We proceed by backward induction. Ex post when state $s$ is realized, the equilibrium allocation solves

$$
\max \sum_{i \in I} \lambda^{i} V_{s}^{i}\left(I_{s}^{i},\left\{P_{j, s}\right\}\right)
$$

subject to

$$
\begin{gathered}
F_{S}\left(\left\{\sum_{i \in I} X_{j, s}^{i}\left(I_{S}^{i},\left\{P_{j, s}\right\}\right)\right\}\right) \leq 0, \\
\Gamma_{S}\left(\left\{P_{j, s}\right\}\right) \leq 0 .
\end{gathered}
$$

The first-order conditions are just as before, given by (6) and (7). This leads to the following result. Proposition 5. For given state s, the solution of the ex-post redistribution planning problem (13) equalizes the social marginal utility of income across agents

$$
\frac{\lambda^{i} V_{I, s}^{i}}{1-\sum_{j \in J_{s}} P_{j, s} X_{I, j, s}^{i} \tau_{j, s}}=\frac{\lambda^{i^{\prime}} V_{I, s}^{i^{\prime}}}{1-\sum_{j \in J_{s}} P_{j, s} X_{I, j, s}^{i^{\prime}} \tau_{j, s}} \quad \forall i \in I, \forall i^{\prime} \in I,
$$

where the wedges $\tau_{j, s}$ must satisfy the weighted average conditions (7).

In particular, ex post, the government equalizes social marginal utilities of income across agents, rather than the private marginal utilities of income. Redistributing towards agents that have a higher marginal propensity to spend on depressed goods (goods with high $\tau_{j, s}$ ) is beneficial. In other words, there are macroeconomic stabilization benefits from redistribution.

The allocation for incomes $\left\{I_{s}^{i}\right\}$, prices $\left\{P_{j, s}\right\}$, consumption $\left\{X_{j, s}^{i}\right\}$, and output $\left\{Y_{j, s}\right\}$ that arises in the ex-post stage coincides with the optimal allocation under commitment, solving (5). This immediately implies that the optimum with commitment is time consistent: the optimal allocation under commitment is an equilibrium allocation of the policy game, and the corresponding equilibrium financial taxes $\left\{\tau_{D}^{i, s}\right\}$ are the same as those required under commitment characterized in Proposition $2{ }^{16,17}$

\section{Unifying Aggregate Demand and Pecuniary Externalities}

Our basic model purposefully assumed away the sort of financial frictions that generate pecuniary externalities, which have already been invoked to justify macroprudential interventions. This allowed us to isolate a new class of externalities, aggregate demand externalities, and to show that they provide an independent rationale for macroprudential policies.

\footnotetext{
${ }^{16}$ Of course, the indeterminacy discussed earlier remains, so that there are many equilibria of the game, but all share the same allocation.

${ }^{17}$ This time consistency of optimal policy result depends on the set of instruments and market structure that we have assumed, on the separability across states of the production function and price constraints, as well as on our assumptions on the number and timing of stages. We have analyzed different sets of assumptions under which optimal policy is not time consistent. Due to space constraints, we cannot include the corresponding analysis in this paper. Instead, we plan to explore these issues further in future work.
} 
However, aggregate demand and pecuniary externalities are not mutually exclusive. In this section, we build a unified model that allows for both forms of externalities and derive their implications for macroprudential interventions. We extend our basic model by introducing the frictions that are known to give rise to pecuniary externalities: incomplete markets and prices in borrowing constraints.

General model with incomplete markets and prices in borrowing constraints. We generalize the budget constraints as follows. Assets are indexed by $a \in A$, where the nominal payoff of asset $a$ in state $s \in S$ is given by the function $Z_{a, s}\left(\left\{P_{j, s}\right\}\right)$ of the vector of all prices $\left\{P_{j, s}\right\}$ in all states. For example, assets with fixed nominal payoffs can be captured by assuming that $Z_{a, s}$ are independent of $\left\{P_{j, s}\right\}$. We allow payoffs to depend on prices to capture indexed debt, or nominal debt in different currencies.

Agent $i$ faces the budget constraints

$$
\begin{gathered}
\sum_{a \in A} D_{a}^{i} Q_{a}\left(1-\tau_{a}^{i}\right) \leq-T^{i}, \\
\sum_{j \in J_{s}} P_{j, s} X_{j, s}^{i} \leq-\hat{T}_{s}^{i}+\sum_{a \in A} D_{a}^{i} Z_{a, s}\left(\left\{P_{j, s}\right\}\right) \quad \forall s \in S,
\end{gathered}
$$

and the additional constraints

$$
\begin{gathered}
\Phi^{i}\left(\left\{D_{a}^{i}\right\} ;\left\{P_{j, s}\right\}\right) \leq 0 \quad \forall i \in I, \\
B_{s}^{i}\left(\left\{X_{j, s}^{i}\right\},\left\{P_{j, s}\right\}\right) \leq 0 \quad \forall i \in I, \forall s \in S .
\end{gathered}
$$

We now allow the function $B_{s}^{i}$ to depend on the vector of prices $\left\{P_{j, s}\right\}$ in state $s$. We also introduce a new vector constraint, $\Phi^{i}\left(\left\{D_{a}^{i}\right\} ;\left\{P_{j, s}\right\}\right) \leq 0$, on the portfolio $\left\{D_{a}^{i}\right\}$ of agent $i$, where $\Phi^{i}$ is convex in $\left\{D_{a}^{i}\right\}$ and can depend on the price vector $\left\{P_{j, s}\right\}$. These two functions allow us to capture borrowing constraints featuring prices.

We define the indirect utility function $V_{s}^{i}\left(I_{s}^{i}, P_{s}\right)$, the Marshallian demand functions $X_{j, s}^{i}\left(I_{s}^{i}, P_{s}\right)$, and the associated Slutsky matrix $S_{k, j, s}^{i}=X_{P_{k}, j, s}^{i}+X_{k, s}^{i} X_{I, j, s}^{i}$. Note that because $B_{s}^{i}$ depends on $\left\{P_{j, s}\right\}$, the Slutsky matrix is not necessarily symmetric and the Roy identity $V_{P_{k}, s}^{i}+X_{k, s}^{i} V_{I, s}^{i}=0$ does not necessarily hold.

Unrestricted lump-sum taxes allow the government to circumvent the incompleteness of markets. To avoid this outcome, we introduce a new constraint

$$
\Omega\left(\left\{\hat{T}_{s}^{i}\right\}\right) \leq 0 .
$$


As before, the government faces standard budget constraints

$$
\begin{aligned}
\sum_{a \in A} D_{a}^{g} Q_{a}+\sum_{i \in I} \sum_{a \in A} D_{a}^{i} Q_{a} \frac{\tau_{a}^{i}}{1+\tau_{a}^{i}} & =\sum_{i \in I} T_{i}, \\
\sum_{j \in J_{s}} P_{j, s} Y_{j, s}+\sum_{i \in I} \hat{T}_{s}^{i}+\sum_{a \in A} D_{a}^{g} Z_{a, s}\left(\left\{P_{j, s}\right\}\right) & =0 \quad \forall s \in S .
\end{aligned}
$$

Planning problem. The planning problem becomes

$$
\max \sum_{i \in I} \sum_{s \in S} \lambda^{i} V_{s}^{i}\left(I_{s}^{i},\left\{P_{j, s}\right\}\right)
$$

subject to

$$
\begin{gathered}
F\left(\left\{\sum_{i \in I} X_{j, s}^{i}\left(I_{s}^{i},\left\{P_{j, s}\right\}\right)\right\}\right) \leq 0, \\
\Gamma\left(\left\{P_{j, s}\right\}\right) \leq 0, \\
I_{s}^{i}=-\hat{T}_{s}^{i}+\sum_{a \in A} D_{a}^{i} Z_{a, s}\left(\left\{P_{j, s}\right\}\right) \quad \forall i \in I, \forall s \in S, \\
\Phi^{i}\left(\left\{D_{a}^{i}\right\} ;\left\{P_{j . s}\right\}\right) \leq 0 \quad \forall i \in I, \\
\Omega\left(\left\{\hat{T}_{s}^{i}\right\}\right) \leq 0 .
\end{gathered}
$$

Optimal policy. The first-order condition with respect to $D_{a}^{i}$ is

$$
\begin{aligned}
& \frac{\sum_{s \in S} \lambda^{i} V_{I, s}^{i} Z_{a, s}}{\sum_{s \in S} \frac{\frac{F_{j^{*}(s), s}}{P_{j^{*}(s), s}} Z_{a, s}}{\sum_{s \in S} \frac{F_{j^{*}(s), s}}{P_{j^{*}(s), s}} Z_{a, s}}\left[1-\sum_{j \in J_{s}} P_{j, s} X_{I, j, s}^{i} \tau_{j, s}\right]} \\
& =\mu \sum_{s \in S} \frac{F_{j^{*}(s), s}}{P_{j^{*}(s), s}} Z_{a, s}+\frac{-\rho^{i} . \Phi_{D_{a}^{i}}^{i}}{\sum_{s \in S} \frac{\frac{F_{j^{*}(s), s}}{P_{j^{*}(s), s}}}{\sum_{s \in S} \in F_{\frac{j^{*}(s), s}{s}}} Z_{a, s}\left[1-\sum_{j \in J_{s}} P_{j, s} X_{I, j, s}^{i} \tau_{j, s}\right]} \quad \forall a \in A, \forall i \in I,
\end{aligned}
$$

where $\rho^{i}$ is the multiplier on the constraint $\Phi^{i}\left(\left\{D_{a}^{i}\right\} ;\left\{P_{j . s}\right\}\right) \leq 0$ and $\Phi_{D_{a}^{i}}^{i}$ is the derivative of the function $\Phi^{i}$ with respect to $D_{a}^{i}$. The first term on the left-hand side still represents the concept of social marginal utility of income. Social marginal utilities of income need not be equalized across agents in all states $s \in S$ because of the portfolio constraints $\Phi^{i}\left(\left\{D_{a}^{i}\right\} ;\left\{P_{j . s}\right\}\right) \leq 0$.

The first order condition for $P_{k, s}$ can be written as follows (using the first order condition for 
$\hat{T}_{s}^{i}$ derived below)

$$
\frac{F_{j^{*}(s), s}}{P_{j^{*}(s), s}} \sum_{i \in I} \sum_{j \in J_{s}} P_{j, s} \tau_{j, s} S_{k, j, s}^{i}=v \cdot \Gamma_{P_{k, s}}+I M_{k, s}+P B_{k, s} \quad \forall s \in S, \forall k \in J_{s},
$$

where

$$
\begin{gathered}
I M_{k, s}=-\sum_{i \in I} X_{k, s}^{i}\left(\omega \cdot \Omega_{\hat{T}_{s}^{i}}\right)+\sum_{a \in A} \sum_{s^{\prime} \in S} \sum_{i \in I} D_{a}^{i} Z_{a, s^{\prime}, P_{k, s}}\left(\omega \cdot \Omega_{\hat{T}_{s^{\prime}}^{i}}\right), \\
P B_{k, s}=-\sum_{i \in I} \lambda^{i}\left[V_{P_{k}, s}^{i}+X_{k, s}^{i} V_{I, s}^{i}\right]-\sum_{i \in I} \rho^{i} \cdot \Phi_{P_{k, s}}^{i} .
\end{gathered}
$$

Here, $\omega$ is the multiplier on the constraint $\Omega\left(\left\{\hat{T}_{s}^{i}\right\}\right) \leq 0$.

The first-order condition for $\hat{T}_{s}^{i}$ is

$$
\frac{\lambda^{i} V_{I, s}^{i}}{1-\sum_{j \in J_{s}} P_{j, s} X_{I, j, s}^{i} \tau_{j, s}}=\frac{\mu F_{j^{*}(s), s}}{P_{j^{*}(s), s}}-\frac{\omega \cdot \Omega_{\hat{T}_{s}^{i}}}{1-\sum_{j \in J_{s}} P_{j, s} X_{I, j, s}^{i} \tau_{j, s}} \quad \forall i \in I, \forall s \in S .
$$

Proposition 6. The solution to the planning problem (14) can be implemented with financial taxes given by

$$
\tau_{a}^{i}=\sum_{s \in S} \frac{\frac{F_{j^{*}(s), s}}{P_{j^{*}(s), s}} Z_{a, s}}{\sum_{s \in S} \frac{F_{j^{*}(s), s}}{P_{j^{*}(s), s}} Z_{a, s}} \tau_{D, s^{\prime}}^{i}
$$

where the virtual taxes $\tau_{i, s}^{D}$ are defined as

$$
\tau_{D, s}^{i}=\sum_{j \in J_{s}} P_{j, s} X_{I, j, s}^{i} \tau_{j, s}
$$

where the wedges $\tau_{j, s}$ must satisfy the weighted average conditions (16), and (17).

Remarkably, the formula for optimal financial taxes in Proposition 6 is exactly the same as in Proposition 2 and its corollary for arbitrary securities. ${ }^{18}$ It is independent of the exact friction: nominal rigidities and constraints on monetary policy; incomplete markets; and prices in borrowing constraints. It applies in environments with aggregate demand externalities, pecuniary externalities, or both. Of course the underlying sufficient statistics (marginal propensities to spend $P_{j, s} X_{I, j, s}^{i}$ and wedges $\tau_{j, s}$ ) depend on the environment. But given these sufficient statistics, the formula for optimal taxes is independent of the details of the environment.

To understand how the different frictions contribute to the wedges $\tau_{j, s}$, it is illuminating to examine the system of equations (16). For each $s \in S$ and $k \in J_{s}$, the left-hand side represents a weighted average of the wedges $\tau_{j, s}$ in state $s$. The right-hand side comprises three terms (on three

\footnotetext{
${ }^{18}$ This exact formula might seem surprising in light of equation (15). The intuition is that for every agent, at the optimal portfolio, these financial taxes align the social and private marginal benefits of any particular feasible marginal trade (i.e. a trade that leaves the portfolio in the feasible set defined by the constraint portfolio constraint $\left.\Phi^{i}\left(\left\{D_{a}^{i}\right\} ;\left\{P_{j . s}\right\}\right) \leq 0\right)$.
} 
different lines), corresponding to the different frictions contributing to non-zero wedges. As before, the first term $v \cdot \Gamma_{P_{k, s}}$, which arises because of nominal rigidities and constraints on monetary policy, is due to the frictions emphasized in our baseline model. The second term $I M_{k, s}$, which arises because of incomplete markets, and the third term $P B_{k, s}$, which arises because of prices in borrowing constraints, are both new and are due to the additional financial frictions introduced in the unified model. Overall, these terms show up as forcing variables in a linear system of equations for wedges $\tau_{j, s}$. Wedges $\tau_{j, s}$ are nonzero to the extent that these forcing variables are nonzero, indicating that the corresponding frictions are binding.

As before, nonzero wedges $\tau_{j, s}$ and differences in marginal propensities to spend $P_{j, s} X_{I, j, s}^{i}$ imply that private financial decisions are suboptimal in the absence of financial taxes. Wedges and marginal propensities to spend are enough to determine optimal financial taxes, independently of the friction or combination of frictions that lead to these wedges.

\section{Applications}

We now study various applications, all of which map exactly into the general models and results from Sections 3 and 4. Our applications illustrate optimal monetary and macroprudential policies in concrete examples. We stress aggregate demand externalities, but also consider pecuniary externalities, as well as their interactions.

\subsection{Liquidity Trap and Deleveraging}

In this section we consider a liquidity trap model with "deleveraging" in the spirit of Eggertsson and Krugman (2012). They study an economy with sticky prices where indebted households are suddenly required to pay down their debt. This amounts to a form of forced savings that lowers the real interest rate that would be prevail with flexible prices, i.e. the "Wicksellian natural interest rate". As long as this natural interest rate remains positive, monetary policy can perfectly stabilize the economy, achieving the flexible price outcome, by setting the nominal interest rate equal to the natural interest rate. However, because nominal interest rates are bounded below by zero, if the deleveraging shock is large enough then the natural real interest rate becomes negative, achieving the flexible price outcome is no longer possible. This generates a liquidity trap: monetary policy finds itself constrained by the zero lower bound, and a recession ensues, with output and employment below their flexible price levels.

Eggertsson and Krugman (2012) take initial debt positions as given. To study macroprudential policies, we extend their model by considering the pre-crisis determination of indebtedness, as well as polices that curb this indebtedness. Indeed, we show that it is optimal to introduce macroprudential limits on borrowing ahead of the crisis, which could in practice take the form of macroprudential regulatory Loan-To-Value (LTV) or Debt-To-Income (DTI) ratios. 
There are a few ways of introducing nominal rigidities. Here, we consider a model with sticky wages rather than sticky prices. We adopt an equal rationing rule in the labor market. These particular choices do not affect our main conclusions. We could have instead assumed sticky wages and efficient rationing, or flexible wages with sticky prices. ${ }^{19}$

To keep things simple, we start with a deterministic model and focus on aggregate demand externalities. We then extend the model to incorporate uncertainty and borrowing constraints that are affected by housing prices, motivated by mortgage lending which takes real estate as collateral. The latter gives rise to pecuniary externalities in addition to aggregate demand externalities.

Households. There are three periods $t \in\{0,1,2\}$ and two types of agents $i \in\{1,2\}$ with relative fractions $\phi^{i}$ in a population of mass 1 . For concreteness it is useful to think of type 1 agents as "savers" and type 2 agents as "borrowers". Periods 1 and 2 represent the economy in Eggertsson and Krugman (2012), with an exogenous binding borrowing constraint on borrowers. We add period 0 where borrowers contract their initial debt with savers.

Agents of type $i$ have preferences over consumption and labor given by

$$
\sum_{t=0}^{2} \beta_{i}^{t}\left[u\left(C_{t}^{i}\right)-v\left(N_{t}^{i}\right)\right]
$$

We assume $\beta_{2} \leq \beta_{1}$ so that agents of type 2 are more impatient than agents of type 1 . As a result, agents of type 1 are natural savers while agents of type 2 are natural borrowers.

Agents of type $i$ face the budget constraints

$$
P_{t} C_{t}^{i}+B_{t}^{i} \leq W_{t} N_{t}^{i}+\frac{1}{1+i_{t}} B_{t+1}^{i}
$$

and $B_{3}^{i}=0$, where $B_{t}^{i}$ represent the nominal debt holdings, $i_{t}$ is the nominal interest rate, and $W_{t}$ is the nominal wage.

In period 1, type-2 agents face a borrowing constraint

$$
B_{2}^{2} \leq P_{2} \bar{B}_{2}
$$

This constraint may arise from contracting imperfections and is assumed to be independent of policy. We are interested in cases where this constraint binds, so that period 1 represents the "deleveraging" stage. In contrast, we assume that borrowing in period 0, during the "credit boom" stage, is unconstrained in the absence of government intervention in credit markets. We consider policy interventions that limit borrowing in the initial period, where the government chooses a maximum debt level $\bar{B}_{1}$ and imposes

$$
B_{1}^{2} \leq P_{1} \bar{B}_{1} .
$$

\footnotetext{
${ }^{19} \mathrm{~A}$ previous version of this paper studies this application assuming sticky prices and flexible wages.
} 
This constraint captures regulations that affect the amount of credit extended to borrowers. ${ }^{20,21}$

The households' first order conditions are

$$
\begin{aligned}
& \frac{1}{1+i_{t}} \frac{P_{t+1}}{P_{t}}=\frac{\beta_{1} u^{\prime}\left(C_{t+1}^{1}\right)}{u^{\prime}\left(C_{t}^{1}\right)}, \\
& \frac{1}{1+i_{t}} \frac{P_{t+1}}{P_{t}} \geq \frac{\beta_{2} u^{\prime}\left(C_{t+1}^{2}\right)}{u^{\prime}\left(C_{t}^{2}\right)},
\end{aligned}
$$

where each inequality holds with equality if the borrowing constraint in period $t$ is slack.

Sticky wages and rationing. We assume sticky wages with $W_{t}=W$ for all $t$. As a result, agents are not necessarily on their labor supply curves, i.e. $W_{t} / P_{t} \neq v^{\prime}\left(N_{t}^{i}\right) / u^{\prime}\left(C_{t}^{i}\right)$. Furthermore, we assume that work is equally rationed: $N_{t}^{1}=N_{t}^{2}=N_{t}$ for all $t$.

Firms. The final good is produced by competitive firms according to the production function

$$
Y_{t}=A N_{t}
$$

Given a nominal wage $W$, perfect competition requires

$$
P_{t}=\frac{W}{A}
$$

Government. The government sets the borrowing limit $\bar{B}_{1}$ in period 0 , and the nominal interest rate $i_{t}$ in every period. In addition, it levies lump-sum taxes in period 0 , which are equivalent to choosing initial debt levels subject to

$$
\phi^{1} B_{0}^{1}+\phi^{2} B_{0}^{2}=0
$$

Equilibrium. An equilibrium specifies quantities for consumption $\left\{C_{t}^{i}\right\}$, labor supply $\left\{N_{t}^{i}\right\}$, debt holding $\left\{B_{t}^{i}\right\}$, prices $\left\{P_{t}\right\}$, wages $W$, nonnegative nominal interest rates $\left\{i_{t}\right\}$, and a borrowing limit $\bar{B}_{1}$ such that households and firms maximize, there is equal rationing $N_{t}^{1}=N_{t}^{2}=N_{t}$, and markets clear,

$$
\sum_{i=1}^{2} \phi^{i} C_{t}^{i}=\sum_{i=1}^{2} \phi^{i} A N_{t} \quad t=0,1,2
$$

These conditions imply that the bond market clears, i.e. $\phi^{1} B_{t}^{1}+\phi^{2} B_{t}^{2}=0$ for all $t$.

The conditions for an equilibrium (18)-(24) act as constraints on the planning problem we study next. However, in a spirit similar to Lucas and Stokey (1983), we seek to drop variables and

\footnotetext{
${ }^{20}$ We could have also imposed a lower bound on debt, but this will not be relevant in the cases that we are interested in. The borrowing constraint effectively allows us to control the equilibrium level of debt $B_{1}^{2}$.

${ }^{21} \mathrm{An}$ alternative formulation that leads to the same results is to tax borrowing to affect the interest rate faced by borrowers.
} 
constraints as follows. Given quantities, equations (21) and (23) can be used to back out certain prices, wages and taxes. Since these variables do not affect welfare they can be dispensed with from our planning problem, along with all the equations except the market clearing condition (24), the borrowing constraint

$$
C_{2}^{2} \geq A N_{2}-\bar{B}_{2}
$$

the Euler equations,

$$
\begin{aligned}
& u^{\prime}\left(C_{t}^{1}\right)=\beta_{1}\left(1+i_{t}\right) u^{\prime}\left(C_{t+1}^{1}\right), \\
& u^{\prime}\left(C_{t}^{2}\right) \geq \beta_{2}\left(1+i_{t}\right) u^{\prime}\left(C_{t}^{2}\right),
\end{aligned}
$$

the complementary slackness condition

$$
\left(C_{2}^{2}-A N_{2}+\bar{B}_{2}\right)\left(u^{\prime}\left(C_{t}^{2}\right)-\beta_{2}\left(1+i_{t}\right) u^{\prime}\left(C_{t}^{2}\right)\right)=0,
$$

and the requirement that nominal interest rates be positive

$$
i_{t} \geq 0 \text {. }
$$

Proposition 7 (Implementability). An allocation $\left\{C_{t}^{i}\right\}$ and $\left\{N_{t}^{1}\right\}$ together with nominal interest rates $\left\{i_{t}\right\}$ forms part of an equilibrium if and only if conditions (24), (25), (26), (27), (28), and (29) hold.

Optimal macroprudential interventions. We now solve the Ramsey problem of choosing the competitive equilibrium that maximizes social welfare, computed as a weighted average of agents utilities, with arbitrary Pareto weights $\lambda^{i}$,

$$
\max \sum_{i=1}^{2} \sum_{t=0}^{2} \lambda^{i} \phi^{i} \beta_{i}^{t}\left[u\left(C_{t}^{i}\right)-v\left(N_{t}\right)\right]
$$

subject to (24)-(29). Henceforth, we are interested in cases where the borrower finds himself borrowing constrained, so that (25) and (28) hold with equality, and (27) holds with strict inequality. We also focus on the possibility that the zero lower bound binds in periods 1 , and assume it does not bind in period 0 .

The first-order conditions of this planning problem deliver a number of useful insights. Define the normalized Pareto weights

$$
\lambda_{t}^{i}=\lambda^{i} \beta_{i}^{t}
$$

Denote by the labor wedge of agents of type $i \in\{1,2\}$ in period $t$ as

$$
\tau_{t}^{i}=1-\frac{v^{\prime}\left(N_{t}^{i}\right)}{A u^{\prime}\left(C_{t}^{i}\right)^{\prime}}
$$


and we define the average labor wedge $\bar{\tau}_{t}$ by

$$
\frac{\bar{\tau}_{t}}{1-\bar{\tau}_{t}}=\sum_{i=1}^{2} \frac{\lambda_{t}^{i} \phi_{i}}{\sum_{j=1}^{2} \lambda_{t}^{i} \phi_{i}} \frac{\tau_{0}^{i}}{1-\tau_{0}^{i}}
$$

First, we can derive a set of equations that characterize the average labor wedge $\bar{\tau}_{t}$. This characterization involves the multiplier $v \leq 0$ on the constraint $u^{\prime}\left(C_{1}^{1}\right)=\beta\left(1+i_{1}\right) u^{\prime}\left(C_{2}^{1}\right)$. This multiplier $v$ is zero when the zero bound constraint $i_{1} \geq 0$ is slack, and is negative otherwise. We have

$$
\begin{gathered}
\bar{\tau}_{0}=0, \\
\frac{\bar{\tau}_{1}}{1-\bar{\tau}_{1}}=\frac{\lambda_{1}^{1} \phi_{1}}{\sum_{i=1}^{2} \lambda_{1}^{i} \phi_{i}} \frac{1}{1-\tau_{1}^{1}} \frac{v}{\lambda_{1}^{1} \phi_{1}} \frac{u^{\prime \prime}\left(C_{1}^{1}\right)}{u^{\prime}\left(C_{1}^{1}\right)}, \\
\frac{\bar{\tau}_{2}}{1-\bar{\tau}_{2}}=-\frac{\lambda_{2}^{1} \phi_{1}}{\sum_{i=1}^{2} \lambda_{2}^{i} \phi_{i}} \frac{1}{1-\tau_{2}^{1}} \frac{v \beta_{1}}{\lambda_{2}^{1} \phi_{1}} \frac{u^{\prime \prime}\left(C_{2}^{1}\right)}{u^{\prime}\left(C_{2}^{1}\right)} .
\end{gathered}
$$

Taken together, these equations imply that $\bar{\tau}_{0}=0, \bar{\tau}_{1} \geq 0$ and $\bar{\tau}_{2} \leq 0$ with strict inequalities if and only if the zero lower bound constraint binds. In other words, when the zero lower bound constraint does not bind we achieve perfect macroeconomic stabilization $\left(\bar{\tau}_{t}=0\right)$ in every period. In contrast, when the zero lower bound binds the economy is in a recession in period $1\left(\bar{\tau}_{1}>0\right)$, in a boom in period $2\left(\bar{\tau}_{2}<0\right)$, and is balanced in period $0\left(\bar{\tau}_{0}=0\right)$. The recession in period 1 occurs because the zero lower bound prevents the reduction in the nominal interest rate $i_{1}$ required to stimulate the economy. The boom in period 2 relaxes the constraint $u^{\prime}\left(C_{1}^{1}\right)=\beta\left(1+i_{1}\right) u^{\prime}\left(C_{2}^{1}\right)$. Intuitively, it overstimulates spending in period 2 , so as to increase spending in period 1 , thus mitigating the recession in period 1.

We now show that borrowing should be restricted in period 0 . That is, that $\bar{B}_{1}$ is set low enough to make constraint $B_{1}^{2} \leq P_{1} \bar{B}_{1}$ bind. Indeed, intertemporal rates of substitution satisfy

$$
\frac{1-\tau_{0}^{B}}{1+i_{0}}=\frac{\beta_{2} u^{\prime}\left(C_{1}^{2}\right)}{u^{\prime}\left(C_{0}^{2}\right)} \quad \text { and } \quad \frac{1}{1+i_{0}}=\frac{\beta_{1} u^{\prime}\left(C_{1}^{1}\right)}{u^{\prime}\left(C_{0}^{1}\right)}
$$

where the implicit macroprudential tax $\tau_{0}^{B}$ is given by

$$
\tau_{0}^{B}=\frac{v}{\lambda_{1}^{1} \phi_{1}} \frac{u^{\prime \prime}\left(C_{1}^{1}\right)}{u^{\prime}\left(C_{1}^{1}\right)}=\bar{\tau}_{1} \frac{1-\tau_{1}^{1}}{1-\bar{\tau}_{1}} \frac{\sum_{i=1}^{2} \lambda_{1}^{i} \phi^{i}}{\lambda_{1}^{1} \phi^{1}},
$$

Here $\bar{\tau}_{1} \geq 0$ and hence $\tau_{0}^{B} \geq 0$ with a strict inequality in both cases if the zero lower bound constraint binds. When the zero lower bound binds, borrowing in period 0 should be restrictedor an equivalent tax on borrowing (subsidy on saving) so that the implicit interest rate faced by borrowers is $\left(1+i_{0}\right) /\left(1-\tau_{0}^{B}\right)$ where $\tau_{0}^{B}>0$. This stimulates spending in period 1 , when the economy is in a recession. Intuitively, restricting borrowing in period 0 reshuffles date- 1 wealth 
away from savers, with a low propensity to spend, towards borrowers, with a high propensity to spend. The resulting increase in spending at date 1 helps stabilize the economy. These stabilization benefits are not internalized by private agents-hence the need for government intervention.

Proposition 8. Consider the planning problem (30). Then at the optimum, the average labor wedges are such that $\bar{\tau}_{0}=0, \bar{\tau}_{1} \geq 0$ and $\bar{\tau}_{2} \leq 0$ with strict inequalities if the zero lower bound constraint binds in period 1. When it is the case, it is optimal to impose a binding borrowing constraint $B_{1}^{2} \leq P_{1} \bar{B}_{1}$ on type-2 agents in period 0 . The equivalent implicit tax on borrowing $\tau_{0}^{B}>0$ is given by $\tau_{0}^{B}=\bar{\tau}_{1} \frac{1-\tau_{1}^{1}}{1-\bar{\tau}_{1}} \frac{\sum_{i=1}^{2} \lambda_{1}^{i} \phi^{i}}{\lambda_{1}^{1} \phi^{1}}$.

Discussion: optimal ex-ante policy mix. An interesting implication of Proposition 8 is that the optimal mix of monetary and macroprudential policy achieves perfect stabilization $\bar{\tau}_{0}=0$ in period 0 . This result can be interpreted as follows. In period 0 , optimal policy is characterized in target form by two first-order conditions: the equation determining $\tau_{0}^{B}$ and the condition that $\bar{\tau}_{0}=0$. Loosely speaking, these two targets correspond to two policy objectives: financial stability and macroeconomic stability. Financial stability is addressed by macroprudential policy. Given macroprudential policy, monetary policy then addresses macroeconomic stability by following the standard targeting rule $\bar{\tau}_{0}=0$ that arises in New-Keynesian models without constraints on monetary policy or financial frictions.

The fact that optimal monetary policy achieves perfect macroeconomic stabilization $\bar{\tau}_{0}=0$ in period 0 shows that there is no need to modify the objectives assigned to monetary policy by the inflation targeting doctrine in order to address financial stability. In particular, it is not optimal to implement tighter monetary policy in period 0 because of financial stability concerns. Financial stability is best addressed with macroprudential policy.

Of course, this conclusion rests on the availability of macroprudential instruments and the assumption that these can be implemented effectively. In practice, there are concerns regarding the implementation of such policies and the incentives they create for evasion and avoidance. One formal way to see that is that macroprudential policies confront different agents with different interest rates. In contrast, monetary policy "gets in all the cracks", as Federal Reserve Board governor Jeremy Stein put it (in a February 7th, 2013 speech), by setting a common market price, the interest rate. ${ }^{22}$

Mapping to the general model. The planning problem (30) is a particular case of the one studied in Section 3.3. There are two states. The first state corresponds to period 0, and the second state to periods 1 and 2. In the first state, the commodities the consumption good and labor in period 0 . In the second state, the commodities are the consumption good and labor in periods 1 and 2.

The constraint on prices is that $P_{t}=W / A$ and that $W_{t}=W$ must be the same in all periods in the period- $t$ numeraire, and that the period- 1 price of a unit of the period-2 numeraire $1 /\left(1+i_{1}\right)$

\footnotetext{
${ }^{22}$ We have characterized optimal monetary policy under the assumption that macroprudential instruments are not available. We show that both $\bar{\tau}_{0}>0$ or $\bar{\tau}_{0}<0$ are then possible, depending on whether engineering a recession by increasing nominal interest rates increases and reduces borrowing.
} 
must be lower than one. In every period, labor is not chosen by agents of either type. The rationing constraint is that $N_{t}^{1}=N_{t}^{2}$ for all $t$.

Proposition 8 can then be seen as an application of Proposition 4. Indeed, it is instructive to see how the general formula of Proposition 4 can be directly applied in the context of this example. In the interest of space, we will omit the corresponding analysis for our other examples.

In the first state, we take the consumption good to be the reference good. For all agents, it is the only chosen good in this period. In the second state, we take the consumption good at date 2 to be the reference good. We call good 2 the date- 2 consumption good and good 1 the date- 1 consumption good. We focus on the case where $i_{1}=0$ and borrowers are borrowing constrained in period 1 . In the second state, the marginal propensity to spend on good 1 for borrowers $M P S_{1}^{2}$ and savers $M P S_{1}^{1}$ are given by

$$
M P S_{1}^{1}=\frac{1}{1+\frac{u^{\prime \prime}\left(C_{1}^{1}\right)}{\beta_{1} u^{\prime \prime}\left(C_{2}^{1}\right)}}<1 \quad \text { and } \quad M P S_{1}^{2}=1 .
$$

Applying the general formula from Proposition 4, which follows from equation (10), we get

$$
1-\tau_{0}^{B}=\frac{1-\tau_{1,2} M P S_{1}^{2}}{1-\tau_{1,2} M P S_{1}^{1}}
$$

where $\tau_{1,2}$ is the wedge of the consumption good at date 1 vis a vis the consumption good at date 2 . This wedge $\tau_{1,2}$ can in turn be computed as a function of the multiplier on the zero lower bound constraint $v$ and to the labor wedges by using the system of equations (11) and (12) ${ }^{23}$

$$
\begin{gathered}
\tau_{1,2}=\frac{\frac{v}{\lambda_{1}^{1} \phi_{1}} \frac{u^{\prime \prime}\left(C_{2}^{1}\right)}{u^{\prime}\left(C_{2}^{1}\right)}+\frac{v}{\lambda_{1}^{1} \phi_{1}} \frac{u^{\prime \prime}\left(C_{1}^{1}\right)}{u^{\prime}\left(C_{1}^{1}\right)}}{1+\frac{v}{\lambda_{1}^{1} \phi_{1}} \frac{u^{\prime \prime}\left(C_{2}^{1}\right)}{u^{\prime}\left(C_{2}^{1}\right)}}, \\
\frac{v}{\lambda_{1}^{1} \phi^{1}} \frac{u^{\prime \prime}\left(C_{1}^{1}\right)}{u^{\prime}\left(C_{1}^{1}\right)}=\bar{\tau}_{1} \frac{1-\tau_{1}^{1}}{1-\bar{\tau}_{1}} \frac{\sum_{i=1}^{2} \lambda_{1}^{i} \phi^{i}}{\lambda_{1}^{1} \phi^{1}} .
\end{gathered}
$$

In these expressions second derivatives of the utility functions appear because they determine Slutsky compensated elasticities. Taken together, these equations can then be manipulated to yield exactly as above

$$
\tau_{0}^{B}=\frac{v}{\lambda_{1}^{1} \phi^{1}} \frac{u^{\prime \prime}\left(C_{1}^{1}\right)}{u^{\prime}\left(C_{1}^{1}\right)}=\bar{\tau}_{1} \frac{1-\tau_{1}^{1}}{1-\bar{\tau}_{1}} \frac{\sum_{i=1}^{2} \lambda_{1}^{i} \phi^{i}}{\lambda_{1}^{1} \phi^{1}} .
$$

\footnotetext{
${ }^{23}$ It is also possible to derive these formulas by directly using the first order conditions of planning problem (30). For example, the intermediate steps to compute $\tau_{1,2}$ are as follows. By definition we have $1-\tau_{1,2}=\frac{\mu_{1}}{\mu_{2}} \frac{1}{1+i_{1}}$ or equivalently $1-\tau_{1,2}=\frac{\mu_{1}}{\mu_{2}}$ since $i_{1}=0$, where $\mu_{t}$ is the multiplier on the resource constraint (24) at date $t$ in the planning problem (30). The first order conditions for $C_{1}^{1}$ and $C_{1}^{2}$ are $\lambda_{1}^{1} u^{\prime}\left(C_{1}^{1}\right)-\frac{v}{\phi_{1}} u^{\prime \prime}\left(C_{1}^{1}\right)=\mu_{1}$ and $\lambda_{2}^{1} u^{\prime}\left(C_{2}^{1}\right)+$ $\frac{\beta_{1} v}{\phi_{1}} u^{\prime \prime}\left(C_{2}^{1}\right)=\mu_{2}$. The result follows.
} 
It is apparent from these formulas that the key determinants of the (implicit) macroprudential tax on borrowing are the differences in marginal propensities to spend $M P S_{1}^{2}$ and $M P S_{1}^{1}$ and the depth of the recession as measured by $\tau_{1,2}$ and commensurate with $\bar{\tau}_{1}$.

We now present a number of extensions of the basic model. All these extensions can be mapped exactly in the general models developed in Sections 3 and 4. In the interest of space, we do not lay down the details of these mappings.

Incorporating uncertainty. We now extend this example to allow for uncertainty. Uncertainty is modeled by a shock $\omega$ realized at date 1 . The realization can be good $\omega=\omega_{G}$ or bad $\omega=\omega_{B}$ with ex-ante probabilities $\pi\left(\omega_{G}\right)$ and $\pi\left(\omega_{B}\right)$. There are complete markets in period 0 so that borrowers and savers can trade state-contingent Arrow-Debreu securities which pay one unit of the numeraire in period 1 if $\omega=\omega_{G}$ and zero otherwise, or one unit of the numeraire in period 1 if $\omega=\omega_{B}$ and zero otherwise.

The realization of $\omega$ determines the borrowing constraint $\bar{B}_{2}(\omega)$, with $\bar{B}_{2}\left(\omega_{G}\right)>\bar{B}_{2}\left(\omega_{B}\right)$. We consider the case where under the optimal policy, the period-1 borrowing constraint and the zero lower bound constraint between periods 1 and 2 are both slack if $\omega=\omega_{G}$, but are both binding if $\omega=\omega_{B}$. Loosely speaking, this example features a credit boom in period 0 , and a credit crunch associated with deleveraging in period 1 in state $\omega_{B}{ }^{24}$

The analysis is similar to that of the deterministic model. When $\omega=\omega_{G}$, the economy is perfectly stabilized with $\bar{\tau}_{1}\left(\omega_{G}\right)=\bar{\tau}_{2}\left(\omega_{G}\right)=0$. When $\omega=\omega_{B}$ instead, the economy experiences a liquidity trap and a recession with $\bar{\tau}_{1}\left(\omega_{B}\right)>0$ and $\bar{\tau}_{2}\left(\omega_{B}\right)<0$ exactly as above. In period 0 , we still have $\bar{\tau}_{0}=0$.

Optimal macroprudential policy imposes no macroprudential tax $\tau_{0}^{B^{\omega_{G}}}=0$ on state-contingent borrowing against state $\omega_{G}$, but a positive macroprudential tax $\tau_{0}^{B_{\omega_{B}}}>0$ on state-contingent borrowing against state $\omega_{B}$ by agents of type 2 , given by the same formulas as above (in particular, we have $\left.\tau_{0}^{B_{\omega_{B}}}=\bar{\tau}_{1}\left(\omega_{B}\right) \frac{1-\tau_{1}^{1}\left(\omega_{B}\right)}{1-\bar{\tau}_{1}\left(\omega_{B}\right)}\left(\lambda_{1}^{1} \phi^{1}+\lambda_{1}^{2} \phi^{2}\right) / \lambda_{1}^{1} \phi^{1}\right)$. The objective of macroprudential policy is to restrict borrowing by type-2 agents against the bad state of the world $\omega_{B}$ with a liquidity trap and a recession, not to restrict borrowing against the good state of the world $\omega_{G}$ with no recession. In this sense, the problem can be seen as one of under-insurance, rather than overborrowing. Note however, that non-contingent borrowing must carry a positive tax, since it embeds a component of borrowing against the bad state of the world $\omega_{B}$. Indeed the corresponding tax on non-contingent borrowing in period 0 is $\tau_{0}^{B}=Q_{\omega_{B}} /\left(Q_{\omega_{G}}+Q_{\omega_{B}}\right) \tau_{0}^{B_{\omega_{B}}}>0$, where $Q_{\omega_{i}}=\pi\left(\omega_{i}\right) \beta_{1} u^{\prime}\left(C_{1}^{1}\left(\omega_{i}\right)\right) / u^{\prime}\left(C_{1}^{1}\left(\omega_{i}\right)\right)$ is the price of the Arrow-Debreu security that pays one in period 1 if $\omega=\omega_{i}$, for $i \in\{G, B\}$. As is natural, this tax is commensurate with the probability

\footnotetext{
${ }^{24}$ It is also possible to allow for differences in beliefs in period 0 by endowing agents with different subjective probabilities. We adopt a practical solution to resolve the associated conceptual normative difficulties by evaluating the welfare of each agent under his subjective probabilities. For example, imagine that agents of type $i$ have subjective probabilities $\pi^{i}\left(\omega_{j}\right)$ with $\pi^{2}\left(\omega_{G}\right)>\pi^{1}\left(\omega_{G}\right)$ so that agents of type 2 (borrowers) are more optimistic than agents of type 1 (savers). Such differences in beliefs generate additional borrowing in period 0 , thereby contributing to the credit boom in period 0 . The analysis is identical.
} 
$\pi\left(\omega_{B}\right)$ of the bad state.

Pecuniary externalities from housing prices. We now extend this example to allow for borrowing constraints that depend on housing prices, capturing their collateral value in mortgage lending.

To simplify, we assume two types of houses. Agents of type $i \in\{1,2\}$ consume housing services of type $i$. There is a mass $\phi_{i}$ of houses of type $i$. Each house generates one unit of housing services. Housing services $H_{t}^{i}$ enter the utility function of agents of type $i$ separably with perperiod utility $h\left(H_{t}^{i}\right)$. The prices for housing services (rents) are perfectly flexible. We denote by $q_{1}^{i}$ the price of one unit of period-2 housing services of type $i$ in terms of the period-1 numeraire. We refer to $q_{1}^{i}$ as the price of houses of type $i$ in period 1. We assume that the borrowing constraint of agents of type 2 (borrowers) in period 1 is such that they can borrow $\kappa q_{1}^{2}$ in units of the period1 consumption good per unit of period-2 housing services that they purchase. The idea is that housing services must be purchased one period in advance, subject to a borrowing constraint which can only potentially bind in period 1. This type of borrowing constraint is common in the literature (see e.g. Kiyotaki and Moore, 1997). As above, we focus on situations where the borrowing constraint and the zero lower bound bind only in period 1 .

In equilibrium, an agent of type $i$ consumes exactly one unit of housing services of type $i$ in each period, and the price of houses of type $i$ in period 1 is given by $q_{1}^{i}=\beta_{i} h^{\prime}(1) / u^{\prime}\left(C_{1}^{i}\right)$, an increasing function of $C_{1}^{i}$ which we denote, with a slight abuse of notation, by $q_{1}^{i}\left(C_{1}^{i}\right)$. The planning problem is then identical to the planning problem (30) with $\bar{B}_{2}$ replaced by $\kappa q_{1}^{2}\left(C_{1}^{2}\right)$. Optimal macroprudential policy is now characterized by

$$
\tau_{0}^{B}=\frac{\frac{v}{\lambda_{1}^{1} \phi^{1}} \frac{u^{\prime \prime}\left(C_{1}^{1}\right)}{u^{\prime}\left(C_{1}^{1}\right)}}{1+\frac{\gamma \kappa}{\lambda_{1}^{2} \phi^{2}} \frac{q_{1}^{2 \prime}\left(C_{1}^{2}\right)}{u^{\prime}\left(C_{1}^{2}\right)}}+\frac{\frac{\gamma \kappa}{\lambda_{1}^{2} \phi^{2}} \frac{q_{1}^{2 \prime}\left(C_{1}^{2}\right)}{u^{\prime}\left(C_{1}^{2}\right)}}{1+\frac{\gamma \kappa}{\lambda_{1}^{2} \phi^{2}} \frac{q_{1}^{2 \prime}\left(C_{1}^{2}\right)}{u^{\prime}\left(C_{1}^{2}\right)}}>0,
$$

where $\gamma>0$ denotes the multiplier on the borrowing constraint and $q_{1}^{2 \prime}\left(C_{1}^{2}\right)$ is the derivative of the price of houses of type 2 with respect to the consumption of agents of type 2 in period 1 . The macroprudential tax on period-0 borrowing by agents of type 2 now corrects for two externalities: an aggregate demand externality as before (the first term) and a new pecuniary externality (the second term).

When borrowers increase their borrowing it lowers their wealth in period 1. This, in turn, reduces aggregate demand because they have a high marginal propensity to spend in period 1 . Lower consumption reduces housing prices in period 1, further tightening the borrowing constraint. This, in turn, further reduces aggregate demand and consumption in period 1, leading to further reductions in housing prices in period 1. This negative feedback loop has the potential to greatly amplify the negative effects of the deleveraging shock. None of these adverse macroeconomic consequences are internalized by borrowers, creating the need for government interven- 
tion.

\subsection{Capital Controls with Fixed Exchange Rates}

In Section 5.1, the constraint on monetary policy was a liquidity trap. In this section, we focus on another constraint on macroeconomic stabilization in environments with nominal rigidities. We consider a two period model of a small open economy with a fixed exchange rate. The domestic economy loses all monetary autonomy: the domestic nominal interest rate must be equal to the foreign interest rate. We show that this creates a role for capital controls to regain monetary autonomy. We refer the reader to Farhi and Werning (2012a) for a full-fledged analysis of capital controls with fixed exchange rates.

Households. There are two periods $t \in\{0,1\}$. We take the foreign-currency price $P_{T, t}^{*}$ of the traded good as given. The domestic-currency price of traded goods is then $P_{T, t}=E P_{T, t}^{*}$. For simplicity, we assume that foreign agents have linear preferences over traded goods and denote by $\left(P_{T, t+1}^{*} / P_{T, t}^{*}\right) /\left(1+i_{t}^{*}\right)$ their discount rate, where $i_{t}^{*}$ is the foreign nominal interest rate. The domestic nominal interest rate can be backed out from the uncovered interest parity condition $\left(1+i_{t}\right)=\left(1+i_{t}^{*}\right)\left(1+\tau_{t}^{B}\right)$ in which capital controls $\tau_{t}^{B}$ (a tax on capital inflows / subsidy on capital outflows) appear as a wedge.

There is a representative domestic agent with preferences over non-traded goods, traded goods and labor given by the expected utility

$$
\sum_{t=0}^{1} \beta^{t} U\left(C_{N T, t}, C_{T, t}, N_{t}\right)
$$

Below we make some further assumptions on preferences.

Households are subject to the following budget constraints

$$
P_{N T} C_{N T, t}+E P_{T, t}^{*} C_{T, t}+E B_{t} \leq W_{t} N_{t}+E P_{T, t}^{*} Y_{T, t}+\Pi_{t}-T_{t}+\frac{1}{\left(1+i_{t}^{*}\right)\left(1+\tau_{t}^{B}\right)} E B_{t+1},
$$

where we impose $B_{2}=0$. Here $P_{N T}$ is the price of non-traded goods which as we will see shortly, does not depend on $t$ due to the assumed price stickiness; $E$ is the nominal exchange rate, $P_{T, t}^{*}$ is the foreign-currency price of the traded good, $E P_{T, t}^{*}$ is the domestic-currency price of traded goods in period $t ; W_{t}$ is the nominal wage in period $t ; Y_{T, t}$ is the endowment of traded goods in period $t ; \Pi_{t}$ represents aggregate profits in period $t ; T_{t}$ is a lump-sum tax (that balances the government budget); $B_{t}$ is short-term debt in the foreign currency.

The households' first order conditions can be written as

$$
\frac{1}{\left(1+i_{t}^{*}\right)\left(1+\tau_{t}^{B}\right)} \frac{P_{T, t+1}^{*}}{P_{T, t}^{*}}=\frac{\beta U_{C_{T, t+1}}}{U_{C_{T}, t}},
$$




$$
\frac{U_{C_{T, t}}}{E P_{T, t}^{*}}=\frac{U_{C_{N T, t}}}{P_{N T}}
$$

and

$$
\frac{W_{t}}{P_{N T}}=\frac{-U_{N, t}}{U_{C_{N T}, t}}
$$

Firms. The traded goods are traded competitively in international markets. The domestic agents have an endowment $Y_{T, t}$ of these traded goods. Non-traded goods are produced in each country by competitive firms that combine a continuum of non-traded varieties indexed by $j \in[0,1]$ using the constant returns to scale CES technology

$$
Y_{N T, t}=\left(\int_{0}^{1} Y_{N T, t}(j)^{1-\frac{1}{\epsilon}} d j\right)^{\frac{1}{1-\frac{1}{\epsilon}}},
$$

with elasticity $\epsilon>1$. Each variety is produced by a monopolist using a linear technology

$$
Y_{N T, t}(j)=A_{t} N_{t}(j)
$$

Each monopolist hires labor in a competitive market with wage $W_{t}$, but pays $W_{t}\left(1+\tau_{L}\right)$ net of a tax on labor. Monopolists must set prices once and for all in period 0 and cannot change them afterwards. The demand for each variety is given by $C_{N T, t}\left(P_{N T}(j) / P_{N T}\right)^{-\epsilon}$ where $P_{N T}=$ $\left(\int\left(P_{N T}(j)\right)^{1-\epsilon} d j\right)^{1 /(1-\epsilon)}$ is the price of non traded goods. We assume that each firm $j$ is owned by a household who sets the price $P_{N T}(j)$ in addition to making its consumption and labor supply decisions. The corresponding price setting conditions are symmetric across $j$ and given by

$$
\begin{gathered}
P_{N T}=\left(1+\tau_{L}\right) \frac{\epsilon}{\epsilon-1} \frac{\sum_{t=0}^{1} \prod_{s=0}^{t-1} \frac{1}{\left(1+i_{s}^{*}\right)\left(1+\tau_{s}^{B}\right)} \frac{W_{t}}{A_{t}} C_{N T, t}}{\sum_{t=0}^{1} \prod_{s=0}^{t-1} \frac{1}{\left(1+i_{s}^{*}\right)\left(1+\tau_{s}^{B}\right)} C_{N T, t}} . \\
\Pi_{t}=\left[P_{N T}-\frac{W_{t}}{A_{t}}\left(1+\tau_{L}\right)\right] C_{N T, t} .
\end{gathered}
$$

Government. The government sets the tax on labor $\tau_{L}$, capital controls $\tau_{t}^{B}$, and in addition, it levies lump-sum taxes $T_{t}$ in period $t$ to balance its budget

$$
T_{t}+\tau_{L} W_{t} N_{t}+\frac{\tau_{t}^{B}}{1+\tau_{t}^{B}} \frac{1}{1+i_{t}^{*}} E_{t} B_{t}=0
$$

Equilibrium. An equilibrium takes as given the price of traded goods $\left\{P_{T, t}^{*}\right\}$, the foreign nominal interest rate $\left\{i_{t}^{*}\right\}$ and the exchange rate $E$. It specifies consumption of traded and non-traded goods $\left\{C_{T, t}, C_{N T, t}\right\}$, labor supply $\left\{N_{t}\right\}$, debt $\left\{B_{t}\right\}$, the price of non-traded goods $P_{N T}$, wages $\left\{W_{t}\right\}$, the labor taxes $\tau_{L}$, capital controls $\left\{\tau_{t}^{B}\right\}$ such that households and firms maximize, the govern- 
ment's budget constraint is satisfied, and markets clear:

$$
C_{N T, t}=A_{t} N_{t}
$$

These conditions imply that the market for traded goods clears.

The conditions for an equilibrium (31)-(38) act as constraints on the planning problem we study next. However, we can drop variables and constraints. Given quantities, equations (32), (34) and (35) can be used to back out certain prices, wages and taxes. Since these variables do not affect welfare they can be dispensed with from our planning problem, along with all the equations except the condition that determines agents' relative consumption of traded and non traded goods (33), the market clearing condition (38), and the country budget constraint for traded goods

$$
P_{T, 0}^{*}\left[C_{T, 0}-Y_{T, 0}\right]+\frac{1}{1+i_{0}^{*}} P_{T, 1}^{*}\left[C_{T, 1}-Y_{T, 1}\right] \leq 0
$$

Proposition 9 (Implementability). An allocation $\left\{C_{T, t}, C_{N T, t}\right\}$ and $\left\{N_{t}\right\}$ together with prices for nontraded goods $\left\{P_{N T}\right\}$ and capital controls $\left\{\tau_{t}^{B}\right\}$, forms part of an equilibrium if and only if equations (33), (38) and (39) hold.

Homothetic Preferences. Next, we characterize the key condition (33) further by making some weak assumptions on preferences. We make two assumptions on preferences: (i) preferences over consumption goods are weakly separable from labor; and (ii) preferences over consumption goods are homothetic. These assumptions imply that

$$
C_{N T, t}=\alpha\left(\frac{P_{T, t}}{P_{N T, t}}\right) C_{T, t},
$$

for some function $\alpha$ that is increasing and differentiable. This conveniently encapsulates the restriction implied by the first order condition (33).

Define the indirect utility function, which encodes utility in period $t$ when the consumption of traded goods is $C_{T, t}$ and the relative price of traded vs. non-traded goods is $p_{t}=P_{T, t} / P_{N T, t}$ as

$$
V\left(C_{T, t}, p_{t}\right)=U\left(\alpha\left(p_{t}\right) C_{T, t}, C_{T, t}, \frac{\alpha\left(p_{t}\right)}{A_{t}} C_{T, t}\right) .
$$

The derivatives of the indirect utility function will prove useful for our analysis. To describe these derivatives, it is useful to first introduce the labor wedge

$$
\tau_{t}=1+\frac{1}{A_{t}} \frac{U_{N, t}}{U_{C_{N T}, t}} .
$$


Proposition 10. The derivatives of the value function are

$$
\begin{aligned}
V_{p}\left(C_{T, t}, p_{t}\right) & =\frac{\alpha_{p, t}}{p_{t}} C_{T, t} U_{C_{T, t}} \tau_{t}, \\
V_{C_{T}}\left(C_{T, t}, p_{t}\right) & =U_{C_{T, t}}\left(1+\frac{\alpha_{t}}{p_{t}} \tau_{t}\right) .
\end{aligned}
$$

These observations about the derivatives and their connection to the labor wedge are borrowed from Farhi and Werning (2012b) and will be key to our results. A private agent values traded goods according to its marginal utility $U_{C_{T}, t}$, but the actual marginal value in equilibrium is $V_{C_{T, t}}$. The wedge between the two equals $\left(\alpha_{t} / p_{t}\right) \tau_{t}=\left(\left(P_{N T} C_{N T, t}\right) /\left(P_{T, t} C_{T, t}\right)\right) \tau_{t}$, the labor wedge weighted by the relative expenditure share of non-traded goods relative to traded goods. We will sometimes refer to it as the weighted labor wedge for short.

In particular, a private agent undervalues traded goods $V_{C_{T, t}}>U_{C_{T, t}}$ whenever the economy is experiencing a recession, in the sense of having a positive labor wedge $\tau_{t}>0$. Conversely, private agents overvalue traded goods $V_{C_{T}, t}<U_{C_{T}, t}$ whenever the economy is booming, in the sense of having a negative labor wedge $\tau_{t}<0$. These effects are magnified when the economy is relatively closed, so that the relative expenditure share of non-traded goods is large.

Optimal macroprudential capital controls. We now solve the Ramsey problem of choosing the competitive equilibrium that maximizes the utility of domestic agents. We have the following planning problem

$$
\max \sum_{t=0}^{1} \beta^{t} V\left(C_{T, t}, \frac{E P_{T, t}^{*}}{P_{N T}}\right)
$$

subject to

$$
P_{T, 0}^{*}\left[C_{T, 0}-Y_{T, 0}\right]+\frac{1}{1+i_{0}^{*}} P_{T, 1}^{*}\left[C_{T, 1}-Y_{T, 1}\right] \leq 0
$$

We have

$$
V_{p, 0} \frac{E P_{T, 0}^{*}}{P_{N T}}+\beta V_{p, 1} \frac{E P_{T, 1}^{*}}{P_{N T}}=0,
$$

which can be rewritten using Proposition 10 as

$$
\alpha_{p, 0} C_{T, 0} U_{C_{T}, 0} \tau_{0}+\beta \alpha_{p, 1} C_{T, 1} U_{C_{T, 1}} \tau_{1}=0,
$$

where $\tau_{t}$ is the labor wedge in period $t$. Taken together, these equations imply that $\tau_{0}$ and $\tau_{1}$ are of opposite signs, so that if the economy is experiencing a recession in period 0 , then it is experiencing a boom in period 1 and vice versa.

We can also derive a condition that characterizes the optimal capital controls. Indeed, we have

$$
\frac{\beta\left(1+i_{0}^{*}\right) \frac{P_{T, 0}^{*}}{P_{T, 1}^{*}} V_{C_{T}, 1}}{V_{C_{T}, 0}}=1,
$$


or equivalently

$$
\frac{\beta\left(1+i_{0}^{*}\right) \frac{P_{T, 0}^{*}}{P_{T, 1}^{*}} U_{C_{T}, 1}\left(1+\frac{\alpha_{1}}{p_{1}} \tau_{1}\right)}{U_{C_{T}, 0}\left(1+\frac{\alpha_{0}}{p_{0}} \tau_{0}\right)}=1,
$$

implying that capital controls should be given by

$$
1+\tau_{0}^{B}=\frac{1+\frac{\alpha_{1}}{p_{1}} \tau_{1}}{1+\frac{\alpha_{0}}{p_{0}} \tau_{0}}
$$

Suppose for example that the economy is in a boom in period $0\left(\tau_{0}<0\right)$ and a recession in period $1\left(\tau_{1}>0\right)$. Then the optimal tax on capital inflows / subsidy on capital outflows is positive $\tau_{0}^{B}>0$. Doing so reduces spending on non-traded goods by domestic agents in period 0 , when the economy is in a boom, and increases it in period 1, when the economy is in a recession. These stabilization benefits are not internalized by private agents-hence the need for government intervention.

Proposition 11. Consider the planning problem (40). Then at the optimum, the labor wedges are such that $\tau_{0}$ and $\tau_{1}$ are of opposite signs. The optimal tax on capital inflows / subsidy on capital outflows is given by

$$
1+\tau_{0}^{B}=\frac{1+\frac{\alpha_{1}}{p_{1}} \tau_{1}}{1+\frac{\alpha_{0}}{p_{0}} \tau_{0}}
$$

Mapping to the general model. The planning problem (40) can be seen as a particular case of the one studied in Section 3. Proposition 11 can then be seen as an application of Proposition 2.

The mapping is as follows. There are two states. The first state corresponds to period 0 , and the second state to period 1 . In the first state, the commodities are the different varieties of the non-traded good, the traded good and labor in period 0 . In the second state, the commodities are the different varieties of the non-traded good, the traded good and labor in period 1.

We use the foreign numeraire. The constraint on prices the requirement that price of the traded good be given by $P_{T, t}^{*}$ in every period in the foreign numeraire, and the requirement that the price of each variety of non-traded good is constant at $P_{N T}^{*}=E P_{N T}$ in the foreign numeraire. The international interest rate $i_{t}^{*}$ simply indexes the discount rate $\left(P_{T, t+1}^{*} / P_{T, t}^{*}\right) /\left(1+i_{t}^{*}\right)$ of risk neutral foreigners who have linear preferences over the traded good.

\subsection{Capital Controls with Flexible Exchange Rates and Collateral Constraints}

In Section 5.2, we considered a small open economy with nominal rigidities and constraints on monetary policy, a fixed exchange rate. In this section, we use a similar model, but focus on the interaction of collateral constraints and nominal rigidities with a flexible exchange rate. Because prices appear in the collateral constraint, the environment is hybrid, comprising both aggregate 
demand and pecuniary externalities. This creates a role for ex-ante macroprudential capital controls in the form of taxes on capital inflows. Collateral constraints and capital controls have been modeled in the literature on "sudden stop" episodes (see e.g. Jeanne and Korinek, 2010; Bianchi, 2011; Korinek, 2011), but this literature focuses on pecuniary externalities and abstracts from nominal rigidities and monetary policy.

Households. There are three periods $t \in\{0,1,2\}$. There is a representative domestic agent with preferences over non-traded goods, traded goods and labor given by the expected utility

$$
\sum_{t=0}^{2} \beta^{t} U\left(C_{N T, t}, C_{T, t}, N_{t}\right)
$$

Below we make some further assumptions on preferences.

We take the foreign-currency price $P_{T, t}^{*}$ of the traded good as given. To capture a small open economy, assume that foreign agents have linear preferences over traded goods and denote by $\left(P_{T, t+1}^{*} / P_{T, t}^{*}\right) /\left(1+i_{t}^{*}\right)$ their discount rate, where $i_{t}^{*}$ is the foreign nominal interest rate. The domestic nominal interest rate is given by the uncovered interest parity condition $1+i_{t}=(1+$ $\left.i_{t}^{*}\right)\left(1+\tau_{t}^{B}\right)$ in which capital controls $\tau_{t}^{B}$ (a tax on capital inflows / subsidy on capital outflows) appear as a wedge. Households are subject to the following budget constraints

$$
P_{N T} C_{N T, t}+E_{t} P_{T, t}^{*} C_{T, t}+\left(1+i_{t-1}^{*}\right)\left(1+\tau_{t-1}^{B}\right) E_{t} B_{t} \leq W_{t} N_{t}+E_{t} P_{T, t}^{*} Y_{T, t}+\Pi_{t}-T_{t}+E_{t} B_{t+1},
$$

where we have imposed $B_{3}=0$. Here $P_{N T}$ is the price of non-traded goods which does not depend on $t$ due to the assumed price stickiness; $E_{t}$ is the nominal exchange rate, $P_{T, t}^{*}$ is the foreign-currency price of the traded good, $E_{t} P_{T, t}^{*}$ is the domestic-currency price of traded goods in period $t ; W_{t}$ is the nominal wage in period $t ; Y_{T, t}$ is the endowment of traded goods in period $t ; \Pi_{t}$ represents aggregate profits in period $t ; T_{t}$ is a lump-sum tax (that balances the government budget); $B_{t}$ is short-term debt in the foreign currency.

We assume that households face a collateral constraint of the form

$$
E_{t} B_{t+1} \leq \kappa_{N T, t} P_{N T, t}+\kappa_{T, t} P_{T, t} .
$$

This type of ad-hoc borrowing constraint is common in the literature (see e.g. Bianchi, 2011).

The households' first order conditions are

$$
\begin{gathered}
\frac{U_{C_{T, t}}}{E_{t} P_{T, t}^{*}}=\frac{U_{C_{N T, t}}}{P_{N T}}, \\
\frac{W_{t}}{P_{N T}}=\frac{-U_{N, t}}{U_{C_{N T,}}},
\end{gathered}
$$




$$
\frac{1}{\left(1+i_{t}^{*}\right)\left(1+\tau_{t}^{B}\right)} \frac{P_{T, t+1}^{*}}{P_{T, t}^{*}} \geq \frac{\beta U_{C_{T, t+1}}}{U_{C_{T, t}}}
$$

with equality if the borrowing constraint is slack at $t$.

Firms. Firms are modeled exactly as in Section 5.2. The traded goods are bought and sold on competitive international markets. The domestic agents have an endowment $Y_{T, t}$ of traded goods. Non-traded goods are produced in each country by competitive firms that combine a continuum of non-traded varieties indexed by using a constant returns to scale CES technology with elasticity of substitution $\epsilon$. Each variety is produced from labor by a domestically-owned monopolist using a linear technology with productivity $A_{t}$.

Each monopolist hires labor in a competitive market with wage $W_{t}$, but pays $W_{t}\left(1+\tau_{L}\right)$ net of a tax on labor. Monopolists set prices once and for all in period 0 and cannot change them afterwards. The associated price setting conditions are symmetric across firms and given by

$$
P_{N T}=\left(1+\tau_{L}\right) \frac{\epsilon}{\epsilon-1} \frac{\sum_{t=0}^{1} \prod_{s=0}^{t-1} \frac{1}{\left(1+i_{s}^{*}\right)\left(1+\tau_{s}^{B}\right)} \frac{W_{t}}{A_{t}} C_{N T, t}}{\sum_{t=0}^{1} \prod_{s=0}^{t-1} \frac{1}{\left(1+i_{s}^{*}\right)\left(1+\tau_{s}^{B}\right)} C_{N T, t}} .
$$

Profits are

$$
\Pi_{t}=\left(P_{N T}-\frac{W_{t}}{A_{t}}\left(1+\tau_{L}\right)\right) C_{N T, t}
$$

Government. The government sets the tax on labor $\tau_{L}$, capital controls $\tau_{t}^{B}$, and in addition, it levies lump-sum taxes $T_{t}$ in period $t$ to balance its budget

$$
T_{t}+\tau_{L} W_{t} N_{t}+\tau_{t-1}^{B}\left(1+i_{t-1}^{*}\right) E_{t} B_{t}=0
$$

Equilibrium. An equilibrium takes as given the price of traded goods $\left\{P_{T, t}^{*}\right\}$ and the foreign nominal interest rate $\left\{i_{t}^{*}\right\}$. It specifies consumption of traded and non-traded goods $\left\{C_{T, t}, C_{N T, t}\right\}$, labor supply $\left\{N_{t}\right\}$, debt $\left\{B_{t}\right\}$, the price of non-traded goods $P_{N T}$, wages $\left\{W_{t}\right\}$, the labor taxes $\tau_{L}$, capital controls $\left\{\tau_{t}^{B}\right\}$ such that households and firms maximize, the government's budget constraint is satisfied, and markets clear:

$$
C_{N T, t}=A_{t} N_{t}
$$

These conditions imply that the market for traded goods clears.

The conditions for an equilibrium (41)-(49) act as constraints on the planning problem we study next. However, we can drop variables and constraints. Given quantities, equations (45), (44) and (46) can be used to back out certain prices, wages and taxes. Since these variables do not affect welfare they can be dispensed with from our planning problem, along with all the equations except the condition that determines agents' relative consumption of traded and non traded goods 
(43), the market clearing condition (49), the country budget constraint for traded goods

$$
C_{T, t}-Y_{T, t} \leq \hat{B}_{t+1}-\hat{B}_{t}\left(1+i_{t}^{*}\right) \frac{P_{T, t}^{*}}{P_{T, t+1}^{*}}
$$

and the borrowing constraint

$$
\hat{B}_{t+1} \leq \kappa_{N T, t} \frac{P_{N T, t}}{E_{t} P_{T, t}^{*}}+\kappa_{T, t}
$$

where we have defined normalized debt $\hat{B}_{t}$ as debt expressed in units of the international price of the traded good $\hat{B}_{t}=B_{t} / P_{T, t}^{*}$.

Proposition 12 (Implementability). An allocation $\left\{C_{T, t}, C_{N T, t}\right\}$ and $\left\{N_{t}\right\}$ together with prices for nontraded goods $\left\{P_{N T}\right\}$ and capital controls $\left\{\tau_{t}^{B}\right\}$, forms part of an equilibrium if and only if equations (43), (49), (50) and (51) hold.

As in Section 5.2, we assume that preferences over consumption goods are weakly separable from labor; and that preferences over consumption goods are homothetic.

Optimal macroprudential capital controls. We now solve the Ramsey problem of choosing the competitive equilibrium that maximizes the utility of domestic agents. We have the following planning problem

$$
\max \sum_{t=0}^{2} \beta^{t} V\left(C_{T, t}, \frac{E_{t} P_{T, t}^{*}}{P_{N T}}\right)
$$

subject to

$$
\begin{aligned}
C_{T, t}-Y_{T, t} & \leq \hat{B}_{t+1}-\hat{B}_{t}\left(1+i_{t}^{*}\right) \frac{P_{T, t}^{*}}{P_{T, t+1}^{*}}, \\
\hat{B}_{t+1} & \leq \kappa_{N T, t} \frac{P_{N T, t}}{E_{t} P_{T, t}^{*}}+\kappa_{T, t} .
\end{aligned}
$$

We have

$$
V_{p, t} \frac{E_{t} P_{T, t}^{*}}{P_{N T}}-v_{t} \kappa_{N T, t} \frac{P_{N T, t}}{E_{t} P_{T, t}^{*}}=0,
$$

where $v_{t}$ is the multiplier on the collateral constraint at $t$, which can be rewritten using Proposition 10 as

$$
\alpha_{p, t} C_{T, t} U_{C_{T, t}} \tau_{t}=v_{t} \kappa_{N T, t} \frac{1}{p_{t}}
$$

where $\tau_{t}$ is the labor wedge in period $t$. This equation characterizes optimal monetary policy in a target form. It implies that $\tau_{t}=0$ if the borrowing constraint is slack at $t$, and that $\tau_{t}>0$ if the collateral constraint is binding at $t$. When the borrowing constraint is slack, optimal monetary policy perfectly stabilizes the economy. But when the collateral constraint is binding, monetary policy faces a meaningful tradeoff between two objectives: macroeconomic stabilization (minimizing labor wedges) and financial stabilization (smoothing consumption). A more depreciated 
exchange rate $E_{t}$ improves the first objective as it stimulates demand, but worsens the second as it tightens the collateral constraint. Optimal monetary policy is therefore a compromise resulting in a recession and a binding collateral constraint.

We can also derive a condition that characterizes the optimal capital controls. Indeed, we have that then

$$
\frac{1}{\beta\left(1+i_{t}^{*}\right)} \frac{P_{T, t+1}^{*}}{P_{T, t}^{*}} \geq \frac{V_{C_{T}, t+1}}{V_{C_{T}, t}}
$$

or equivalently

$$
\frac{1}{\beta\left(1+i_{t}^{*}\right)} \frac{P_{T, t+1}^{*}}{P_{T, t}^{*}} \geq \frac{U_{C_{T}, t+1}\left(1+\frac{\alpha_{t+1}}{p_{t+1}} \tau_{t+1}\right)}{U_{C_{T}, t}\left(1+\frac{\alpha_{t}}{p_{t}} \tau_{t}\right)},
$$

with equality if the borrowing constraint is not binding at $t$, implying that capital controls should be given by

$$
1+\tau_{t}^{B}=\frac{1+\frac{\alpha_{t+1}}{p_{t+1}} \tau_{t+1}}{1+\frac{\alpha_{t}}{p_{t}} \tau_{t}} .
$$

Suppose for example that the borrowing constraint is slack in period 0 but binding in period 1. Then optimal monetary policy stabilizes the economy in period $0\left(\tau_{0}=0\right)$ but engineers a recession in period $1\left(\tau_{1}>0\right)$. Then the optimal tax on capital inflows / subsidy on capital outflows is positive $\tau_{0}^{B}>0$. Doing so increases spending on non-traded goods by domestic agents in period 1 when the economy is in a recession. These stabilization benefits are not internalized by private agents-hence the need for government intervention.

Proposition 13. Consider the planning problem (52). The optimal tax on capital inflows / subsidy on capital outflows is given by

$$
1+\tau_{t}^{B}=\frac{1+\frac{\alpha_{t+1}}{p_{t+1}} \tau_{t+1}}{1+\frac{\alpha_{t}}{p_{t}} \tau_{t}},
$$

where $\tau_{t}>0$ if and only if the collateral constraint is binding at $t$.

Mapping to the general model. The planning problem (52) can be seen as a particular case of the one studied in Section 4. Proposition 11 can then be seen as an application of Proposition 6.

The mapping is as follows. There are three states. The first state corresponds to period 0 , the second state to period 1, and the third state to period 2. In each state, the commodities are the different varieties of the non-traded good, the traded good and labor in the corresponding period.

We use the foreign numeraire. The constraint on prices the requirement that price of the traded good be given by $P_{T, t}^{*}$ in every period in the foreign numeraire. The international interest rate $i_{t}^{*}$ simply indexes the discount rate $\left(P_{T, t+1}^{*} / P_{T, t}^{*}\right) /\left(1+i_{t}^{*}\right)$ of risk neutral foreigners who have linear preferences over the traded good. The fact that the price of each variety of non-traded good is constant at $P_{N T}$ in the domestic numeraire or $P_{N T, t}^{*}=P_{N T} / E_{t}$ in the foreign numeraire simply defines the exchange rate $E_{t}$. 
There is a complete set of Arrow-Debreu securities. The portfolio constraints are the requirement that $B_{t+1} \leq \kappa_{N T, t} P_{N T, t}^{*}+\kappa_{T, t} P_{T, t}^{*}$. These constraints depend on prices.

\subsection{Capital Controls with Flexible Exchange Rates and Local and Foreign- Currency Debt}

In Section 5.3, we considered a hybrid model of a small open economy with flexible exchange rates and collateral constraints that depend on prices, featuring both aggregate demand and pecuniary externalities. In this section, we analyze another hybrid environment, where pecuniary externalities arise from incomplete markets, instead of collateral constraints. We consider a small open economy model with two periods subject to uncertainty. Markets are incomplete: only localand foreign-currency debt can be traded. This creates a for role macroprudential capital controls. Interestingly, optimal policy calls for different taxes on local- and foreign-currency debt. Under natural conditions, taxes on foreign currency debt are higher than on local-currency debt, consistent with a standard view that international credit booms fueled by foreign-currency debt are particularly problematic.

Households. There are two periods $t \in\{0,1\}$. States of the world $s_{1} \in S_{1}$ occur with probability $\pi\left(s_{1}\right)$. We leave the dependence of variables on $s_{1}$ implicit whenever possible. Expectations at date 0 are denoted by $\mathbb{E}_{0}$.

We take the foreign-currency price $P_{T, t}^{*}$ of the traded good as given. For simplicity, we assume that foreign agents are risk neutral with linear preferences over traded goods and denote by $\left(P_{T, t+1}^{*} / P_{T, t}^{*}\right) /\left(1+i_{t}^{*}\right)$ their discount rate, where $i_{t}^{*}$ is the foreign nominal interest rate.

There is a representative domestic agent with preferences

$$
\mathbb{E}_{0} \sum_{t=0}^{1} \beta^{t} U\left(C_{N T, t}, C_{T, t}, N_{t}\right)
$$

Below we make some further assumptions on preferences.

Households are subject to the following budget constraints

$$
\begin{aligned}
P_{N T} C_{N T, t}+E_{t} P_{T, t}^{*} C_{T, t}+E_{t} B_{t}^{F}+B_{t}^{H} & \\
& \leq W_{t} N_{t}+E_{t} P_{T, t}^{*} Y_{T, t}+\Pi_{t}-T_{t}+\frac{1}{\left(1+i_{t}^{*}\right)\left(1+\tau_{t}^{B^{F}}\right)} E_{t} B_{t+1}^{F}+\frac{1}{1+i_{t}} B_{t+1}^{H},
\end{aligned}
$$

where we impose $B_{2}^{F}=B_{2}^{H}=0$. Here $P_{N T}$ is the price of non-traded goods which as we will see shortly, does not depend on $t$ due to the assumed price stickiness; $E$ is the nominal exchange rate, $P_{T, t}^{*}$ is the foreign-currency price of the traded good, $E P_{T, t}^{*}$ is the domestic-currency price of traded goods in period $t ; W_{t}$ is the nominal wage in period $t ; Y_{T, t}$ is the endowment of traded 
goods in period $t ; \Pi_{t}$ represents aggregate profits in period $t ; T_{t}$ is a lump-sum tax (that balances the government budget); $B_{t}^{F}$ is short-term debt in the foreign currency; $B_{t}^{H}$ is short-term debt in the local currency; $i_{t}^{*}$ is the foreign nominal interest rate; $i_{t}$ is the domestic interest rate; and $\tau_{t}^{B^{F}}$ is the capital control tax on foreign-currency debt.

We also introduce a capital control tax $\tau_{t}^{B^{H}}$ on local-currency debt. The uncovered interest parity equation which must hold despite the presence of risk because the rest of the world is risk neutral, but with a wedge introduced by capital controls

$$
\left(1+i_{t}\right) \mathbb{E}_{t}\left[\frac{E_{t}}{E_{t+1}}\right]=\left(1+\tau_{t}^{B^{H}}\right)\left(1+i_{t}^{*}\right)
$$

The households' first order conditions are

$$
\begin{gathered}
1=\mathbb{E}_{t}\left[\frac{\beta U_{C_{T}, t+1}}{U_{C_{T}, t}}\left(1+i_{t}^{*}\right)\left(1+\tau_{t}^{B^{F}}\right) \frac{P_{T, t}^{*}}{P_{T, t+1}^{*}}\right], \\
1=\mathbb{E}_{t}\left[\frac{\beta U_{C_{T}, t+1}}{U_{C_{T}, t}}\left(1+i_{t}\right) \frac{E_{t}}{E_{t+1}} \frac{P_{T, t}^{*}}{P_{T, t+1}^{*}}\right], \\
\frac{U_{C_{T}, t}}{E_{t} P_{T, t}^{*}}=\frac{U_{C_{N T}, t}}{P_{N T}}, \\
\frac{W_{t}}{P_{N T}}=\frac{-U_{N, t}}{U_{C_{N T}, t}} .
\end{gathered}
$$

Firms. Firms are modeled exactly as in Section 5.2. The traded goods are traded competitively in international markets. The domestic agents have an endowment $Y_{T, t}$ of these traded goods. Non-traded goods are produced in each country by competitive firms that combine a continuum of non-traded varieties indexed by using a constant returns to scale CES technology with elasticity of substitution $\epsilon$. Each variety is produced from labor by a domestically-owned monopolist using a linear technology with productivity $A_{t}$.

Each monopolist hires labor in a competitive market with wage $W_{t}$, but pays $W_{t}\left(1+\tau_{L}\right)$ net of a tax on labor. Monopolists must set prices once and for all in period 0 and cannot change them afterwards. The associated price setting conditions are symmetric across firms and given by

$$
P_{N T}=\left(1+\tau_{L}\right) \frac{\epsilon}{\epsilon-1} \frac{\sum_{t=0}^{1} \prod_{s=0}^{t-1} \frac{1}{\left(1+i_{s}^{*}\right)\left(1+\tau_{s}^{B}\right)} \frac{W_{t}}{A_{t}} C_{N T, t}}{\sum_{t=0}^{1} \prod_{s=0}^{t-1} \frac{1}{\left(1+i_{s}^{*}\right)\left(1+\tau_{s}^{B}\right)} C_{N T, t}}
$$

Profits are then given by

$$
\Pi_{t}=\left[P_{N T}-W_{t}\left(1+\tau_{L}\right)\right] C_{N T, t} .
$$


Government. The government sets the tax on labor $\tau_{L}$, capital controls on foreign-currency debt $\tau_{t}^{B^{F}}$ and local-currency debt $\tau_{t}^{B^{H}}$, and in addition, it levies lump-sum taxes $T_{t}$ in period $t$ to balance its budget

$$
T_{t}+\tau_{L} W_{t} N_{t}+\frac{\tau_{t}^{B^{F}}}{1+\tau_{t}^{B^{F}}} \frac{1}{1+i_{t}^{*}} E_{t} B_{t}^{F}+\frac{\tau_{t}^{B^{H}}}{1+\tau_{t}^{B^{H}}} \frac{1}{1+i_{t}} B_{t}^{F}=0
$$

Equilibrium. An equilibrium takes as given the price of traded goods $\left\{P_{T, t}^{*}\right\}$ and the foreign nominal interest rate $\left\{i_{t}^{*}\right\}$. It specifies consumption of traded and non-traded goods $\left\{C_{T, t}, C_{N T, t}\right\}$, labor supply $\left\{N_{t}\right\}$, local and foreign-currency debt $\left\{B_{t}^{H}, B_{t}^{F}\right\}$, the price of non-traded goods $P_{N T}$, wages $\left\{W_{t}\right\}$, the labor taxes $\tau_{L}$, capital controls $\left\{\tau_{t}^{B^{F}}, \tau_{t}^{B^{H}}\right\}$ such that households and firms maximize, the government's budget constraint is satisfied, and markets clear:

$$
C_{N T, t}=A_{t} N_{t}
$$

These conditions imply that the market for traded goods clears.

The conditions for an equilibrium (53)-(62) act as constraints on the planning problem we study next. However, exactly as in Section 5.1 we can drop variables and constraints. Given quantities, equations (54), (55), (56), (58) and (59) can be used to back out certain prices, wages and taxes. Since these variables do not affect welfare they can be dispensed with from our planning problem, along with all the equations except the condition that determines agents' relative consumption of traded and non traded goods (57), the market clearing condition (62), and the country budget constraint for traded goods

$$
\begin{gathered}
C_{T, 0}+B_{0}^{F} \frac{1}{P_{T, 0}^{*}}+B_{0}^{H} \frac{1}{E_{0} P_{T, 0}^{*}} \leq Y_{T, 0}+\frac{1}{1+i_{0}^{*}} B_{1}^{F} \frac{1}{P_{T, 0}^{*}}+\frac{1}{\left(1+i_{0}^{*}\right)} \mathbb{E}_{0}\left[\frac{1}{E_{1}}\right] \frac{B_{1}^{H}}{P_{T, 0}^{*}}, \\
C_{T, 1}+B_{1}^{F} \frac{1}{P_{T, 1}^{*}}+B_{1}^{H} \frac{1}{E_{1} P_{T, 1}^{*}} \leq Y_{T, 1} .
\end{gathered}
$$

Proposition 14 (Implementability). An allocation $\left\{C_{T, t}, C_{N T, t}\right\}$ and $\left\{N_{t}\right\}$ together with prices for nontraded goods $\left\{P_{N T}\right\}$ and capital controls $\left\{\tau_{t}^{B^{F}}, \tau_{t}^{B^{H}}\right\}$, forms part of an equilibrium if and only if equations (57), (62), (63) and (64) hold.

As in Sections 5.2 and 5.3, we assume that preferences over consumption goods are weakly separable from labor; and that preferences over consumption goods are homothetic.

Optimal macroprudential capital controls. We now solve the Ramsey problem of choosing the competitive equilibrium that maximizes the utility of domestic agents. We have the following planning problem

$$
\max \sum_{t=0}^{1} \beta^{t} V\left(C_{T, t}, \frac{E_{t} P_{T, t}^{*}}{P_{N T}}\right)
$$


subject to

$$
\begin{gathered}
C_{T, 0}+B_{0}^{F} \frac{1}{P_{T, 0}^{*}}+B_{0}^{H} \frac{1}{E_{0} P_{T, 0}^{*}} \leq Y_{T, 0}+\frac{1}{1+i_{0}^{*}} B_{1}^{F} \frac{1}{P_{T, 0}^{*}}+\frac{1}{\left(1+i_{0}^{*}\right)} \mathbb{E}_{0}\left[\frac{1}{E_{1}}\right] \frac{B_{1}^{H}}{P_{T, 0}^{*}}, \\
C_{T, 1}+B_{1}^{F} \frac{1}{P_{T, 1}^{*}}+B_{1}^{H} \frac{1}{E_{1} P_{T, 1}^{*}} \leq Y_{T, 1} .
\end{gathered}
$$

We have

$$
\begin{gathered}
V_{p, 0} \frac{E_{0} P_{T, 0}^{*}}{P_{N T}}+V_{C_{T}, 0} B_{0}^{H} \frac{1}{E_{0} P_{T, 0}^{*}}=0, \\
V_{p, 1} \frac{E_{1} P_{T, 1}^{*}}{P_{N T}}+V_{C_{T}, 1} B_{1}^{H} \frac{1}{E_{1} P_{T, 1}^{*}}-\frac{V_{C_{T}, 0}}{\beta} \frac{1}{1+i_{0}^{*}} \frac{\pi\left(s_{1}\right)}{E_{1}} \frac{B_{1}^{H}}{P_{T, 0}^{*}}=0,
\end{gathered}
$$

which can be rewritten using Proposition 10 as

$$
\begin{gathered}
\alpha_{p, 0} C_{T, 0} U_{C_{T}, 0} \tau_{0}+V_{C_{T}, 0} B_{0}^{H} \frac{1}{E_{0} P_{T, 0}^{*}}=0, \\
\alpha_{p, 1} C_{T, 1} U_{C_{T, 1} \tau_{1}}+V_{C_{T}, 1} B_{1}^{H} \frac{1}{E_{1} P_{T, 1}^{*}}-\frac{V_{C_{T}, 0}}{\beta} \frac{1}{1+i_{0}^{*}} \frac{\pi\left(s_{1}\right)}{E_{1}} \frac{B_{1}^{H}}{P_{T, 0}^{*}}=0 .
\end{gathered}
$$

where $\tau_{t}$ is the labor wedge in period $t$. These equations characterize optimal monetary policy in a target form. Monetary policy has to navigate a tradeoff between macroeconomic stabilization (targeting a value of zero for $\tau_{t}$ ) and risk sharing (the exchange rate affects the return of localcurrency debt). The first equation shows that $\tau_{0}<0$ if initial local-currency debt is positive $B_{0}^{H}>0$ and $\tau_{0}<0$ otherwise. Optimal monetary policy depreciates the exchange rate more than would be warranted for macroeconomic stability, delivering a boom $\tau_{0}<0$, in order to lower debt repayments to foreigners. The first two terms in the second equation are identical to the first equation. The third term $-V_{C_{T}, 0} /\left(\beta\left(1+i_{0}^{*}\right)\right)\left(\pi\left(s_{1}\right) / E_{1}\right)\left(B_{1}^{H} / P_{T, 0}^{*}\right)$ arises because depreciating the exchange rate in state $s_{1}$ at date 1 is anticipated at date 0 and increases the interest rate on localcurrency debt at date 0 , an effect which optimal monetary policy takes into account.

We can also derive a condition that characterizes the optimal capital controls. Indeed, we have

$$
\begin{gathered}
\mathbb{E}_{0}\left[\frac{\beta V_{C_{T}, 1}}{V_{C_{T}, 0}}\left(1+i_{0}^{*}\right) \frac{P_{T, 0}^{*}}{P_{T, 1}^{*}}\right]=1, \\
\mathbb{E}_{0}\left[\frac{\beta V_{C_{T}, 1}}{V_{C_{T}, 0}}\left(1+i_{0}^{*}\right) \frac{P_{T, 0}^{*}}{P_{T, 1}^{*}} \frac{\frac{1}{E_{1}}}{\mathbb{E}_{0}\left[\frac{1}{E_{1}}\right]}\right]=1,
\end{gathered}
$$


or equivalently using Proposition $10,{ }^{25}$

$$
\begin{gathered}
\mathbb{E}_{0}\left[\frac{\beta U_{C_{T}, 1}}{U_{C_{T}, 0}} \frac{1+\frac{\alpha_{1}}{p_{1}} \tau_{1}}{1+\frac{\alpha_{0}}{p_{0}} \tau_{0}}\left(1+i_{0}^{*}\right) \frac{P_{T, 0}^{*}}{P_{T, 1}^{*}}\right]=1, \\
\mathbb{E}_{0}\left[\frac{\beta U_{C_{T, 1}}}{U_{C_{T}, 0}} \frac{1+\frac{\alpha_{1}}{p_{1}} \tau_{1}}{1+\frac{\alpha_{0}}{p_{0}} \tau_{0}}\left(1+i_{0}^{*}\right) \frac{P_{T, 0}^{*}}{P_{T, 1}^{*}} \frac{\frac{1}{p_{1}}}{\mathbb{E}_{0}\left[\frac{1}{p_{1}}\right]}\right]=1 .
\end{gathered}
$$

Proposition 15. Consider the planning problem (65). The optimal tax on capital inflows / subsidy on capital outflows on foreign- and local-currency debt are given by

$$
\begin{gathered}
1+\tau_{0}^{B^{F}}=\mathbb{E}_{0}\left[\frac{1+\frac{\alpha_{1}}{p_{1}} \tau_{1}}{1+\frac{\alpha_{0}}{p_{0}} \tau_{0}}\right]+\frac{\operatorname{cov}_{0}\left[\frac{\beta U_{C_{T}, 1}}{U_{C_{T}, 0}}, \frac{1+\frac{\alpha_{1}}{p_{1}} \tau_{1}}{1+\frac{\alpha_{0}}{p_{0}} \tau_{0}}\right]}{\mathbb{E}_{0}\left[\frac{\beta U_{C_{T}, 1}}{U_{C_{T}, 0}} \frac{1+\frac{\alpha_{1}}{p_{1}} \tau_{1}}{1+\frac{\alpha_{0}}{p_{0}} \tau_{0}}\right]}, \\
1+\tau_{0}^{B^{H}}=\mathbb{E}_{0}\left[\frac{1+\frac{\alpha_{1}}{p_{1}} \tau_{1}}{1+\frac{\alpha_{0}}{p_{0}} \tau_{0}}\right]+\frac{\operatorname{cov}_{0}\left[\frac{\beta U_{C_{T, 1}, 1}}{U_{C_{T}, 0}} \frac{\frac{1}{p_{1}}}{\mathbb{E}_{0}\left[\frac{1}{p_{1}}\right]}, \frac{1+\frac{\alpha_{1}}{p_{1}} \tau_{1}}{1+\frac{\alpha_{0}}{p_{0}} \tau_{0}}\right]}{\mathbb{E}_{0}\left[\frac{\beta U_{C_{T_{T}, 1}}}{U_{C_{T}, 0}} \frac{\frac{1}{p_{1}}}{\mathbb{E}_{0}\left[\frac{1}{p_{1}}\right]}, \frac{1+\frac{\alpha_{1}}{p_{1}} \tau_{1}}{1+\frac{\alpha_{0}}{p_{0}} \tau_{0}}\right]} .
\end{gathered}
$$

This shows that capital controls on local and foreign-currency debt should be different in general. Indeed, the first (expectation) terms on the right-hand side of these formulas coincide, but the second (covariance) terms differ. The expectation terms simply capture that international borrowing in either local- or foreign-currency debt should be discouraged if the economy is more depressed at date 1 than at date 0 , i.e. if labor wedges $\tau_{t}$ are on average higher at date 1 than at date 0 . This reallocates spending from date 0 to date 1 and helps stabilize the economy. The covariance terms capture the effects of borrowing in foreign- or local-currency debt across states at date 1. There is a force pushing towards a higher capital control tax on foreign-currency debt than on local-currency debt if the terms of trade tend to depreciate in states of the world $s_{1} \in S_{1}$ that feature larger recessions, i.e. if $1 / p_{1}$ co-moves negatively with $\tau_{1}$-a natural configuration.

Mapping to the general model. The planning problem (65) can be seen as a particular case of the one studied in Section 4. Proposition 15 can then be seen as an application of Proposition 6.

The mapping is as follows. There are $\# S_{1}+1$ states. The first state corresponds to period 0 , and the remaining $\# S_{1}$ states correspond to the different states $s_{1} \in S_{1}$ in period 1 . In the first state, the commodities are the different varieties of the non-traded good, the traded good and labor in period 0 . In each remaining state corresponding to $s_{1} \in S_{1}$, the commodities are the different varieties of the non-traded good, the traded good and labor in state $s_{1}$ in period 1 .

\footnotetext{
${ }^{25}$ We use the fact that $\frac{\frac{1}{E_{1}}}{\mathbb{E}_{0}\left[\frac{1}{E_{1}}\right]}=\frac{\frac{1}{p_{1}}}{\mathbb{E}_{0}\left[\frac{1}{p_{1}}\right]}$.
} 
We use the foreign numeraire. The constraint on prices are as follows. The price of the traded good is given by $P_{T, t}^{*}$ in every period in the foreign numeraire. The international interest rate $i_{t}^{*}$ simply indexes the discount rate $\left(P_{T, t+1}^{*} / P_{T, t}^{*}\right) /\left(1+i_{t}^{*}\right)$ of risk neutral foreigners who have linear preferences over consumption goods. The fact that the price of each variety of non-traded good is constant at $P_{N T}$ in the domestic numeraire simply defines the exchange rate $E_{t}=P_{N T} / P_{N T, t}^{*}$.

There are incomplete markets with only local and foreign-currency debt. The dependency of their returns on prices is captured by the $Z_{a, s}$ functions. There are neither portfolio constraints nor borrowing constraints.

\section{Conclusion}

We developed a new general theoretical foundation for macroprudential policies. Our theory is based on a key friction relative to the Arrow-Debreu model: nominal rigidities in goods and labor markets, possibly interacted with constraints on monetary policy such as the zero lower bound or fixed exchange rates. We have shown that in general, competitive equilibria are constrained inefficient. The underlying market failures can be traced to aggregate demand externalities.

Government intervention in financial markets in the form of financial taxes or quantity restrictions generate Pareto improvements, and optimal interventions are characterized by simple and interpretable formulas expressed in terms of empirically measurable sufficient statistics.

We also incorporated financial markets frictions to combine aggregate demand and pecuniary externalities in a single framework. All our results carry over to this hybrid model. Finally, we provided a various relevant applications.

\section{A Appendix}

\section{A.1 Proof of Proposition 2}

We use

$$
\sum_{j \in J_{s}} P_{j, s} X_{I, j, s}^{i}=1
$$

to get for any $\lambda_{s}$

$$
\lambda^{i} V_{I, s}^{i}=\left[\sum_{j \in J_{s}}\left(\mu F_{j, s}-\lambda_{s} P_{j, s}\right) X_{I, j, s}^{i}+\lambda_{s}\right],
$$

and in particular for $\lambda_{s}=\frac{\mu F_{j^{*}(s), s}}{P_{j^{*}(s), s}}$, we get

$$
\lambda^{i} V_{I, s}^{i}=\frac{\mu F_{j^{*}(s), s}}{P_{j^{*}(s), s}}\left[\sum_{j \in J_{s}}\left(P_{j^{*}(s), s} \frac{\mu F_{j, s}}{\mu F_{j^{*}(s), s}}-P_{j, s}\right) X_{I, j, s}^{i}+1\right] .
$$


We can re-express this as

$$
\lambda^{i} V_{I, s}^{i}=\frac{\mu F_{j^{*}(s), s}}{P_{j^{*}(s), s}}\left[1-\sum_{j \in J_{s}} P_{j, s} X_{I, j, s}^{i} \tau_{j, s}\right] .
$$

We use

$$
\begin{gathered}
V_{P_{k}, s}^{i}=-X_{k, s}^{i} V_{I, s}^{i} \\
S_{k, j, s}^{i}=X_{P_{k}, j, s}^{i}+X_{k, s}^{i} X_{I, j, s}^{i}, \\
\sum_{j \in J_{s}} P_{j, s} X_{P_{k, j}, s}^{i}+X_{k, s}^{i}=0, \\
\sum_{j \in J_{s}} P_{j, s} X_{I, j, s}^{i}=1,
\end{gathered}
$$

to get

$$
\begin{aligned}
& -v \cdot \Gamma_{P_{k, s}}=\sum_{i \in I} \sum_{j \in J_{s}} \mu F_{j, s}\left[X_{P_{k}, j, s}^{i}+X_{k, s}^{i} X_{I, j, s}^{i}\right] \\
& -v \cdot \Gamma_{P_{k, s}}=\sum_{i \in I} \sum_{j \in J_{s}}\left(\mu F_{j, s}-\lambda_{s} P_{j, s}\right)\left[X_{P_{k}, j, s}^{i}+X_{k, s}^{i} X_{I, j, s}^{i}\right] \\
& -\sum_{i \in I} \lambda_{s} X_{k, s}^{i}+\sum_{i \in I} \sum_{j \in J_{s}} \lambda_{s} P_{j, s} X_{k, S}^{i} X_{I, j, s^{\prime}}^{i} \\
& -v \cdot \Gamma_{P_{k, s}}=\sum_{i \in I} \frac{\mu F_{j^{*}(s), s}}{P_{j^{*}(s), s}} \sum_{j \in J_{s}}\left(P_{j^{*}(s), s} \frac{\mu F_{j, s}}{\mu F_{j^{*}(s), s}}-P_{j, s}\right)\left[X_{P_{k}, j, s}^{i}+X_{k, s}^{i} X_{I, j, s}^{i}\right] \\
& -\sum_{i \in I} \frac{\mu F_{j^{*}(s), s}}{P_{j^{*}(s), s}} X_{k, s}^{i}+\sum_{i \in I} \sum_{j \in J_{s}} \frac{\mu F_{j^{*}(s), s}}{P_{j^{*}(s), s}} P_{j, s} X_{k, s}^{i} X_{I, j, s}^{i}
\end{aligned}
$$

and finally

$$
-v \cdot \Gamma_{P_{k, s}}=-\sum_{i \in I} \frac{F_{j^{*}}(s), s}{P_{j^{*}(s), s}} \sum_{j \in J_{s}} P_{j, s} \tau_{j, s} S_{k, j, s}^{i} \cdot
$$

Summing up, we have

$$
\begin{gathered}
\lambda^{i} V_{I, s}^{i}=\frac{\mu F_{j^{*}(s), s}}{P_{j^{*}(s), s}}\left[1-\sum_{j \in J_{s}} P_{j, s} X_{I, j, s}^{i} \tau_{j, s}\right], \\
v \cdot \Gamma_{P_{k, s}}=\sum_{i \in I} \frac{\mu F_{j^{*}(s), s}}{P_{j^{*}(s), s}} \sum_{j \in J_{s}} P_{j, s} \tau_{j, s} S_{k, j, s}^{i} .
\end{gathered}
$$




\section{A.2 Proof of Proposition 3}

We treat the case without set restrictions $B_{s}^{i}$. The case where these restrictions are imposed can be perfectly approximated as a limit of economies where the individual utility functions are $U^{i}\left(\left\{X_{j, s}^{i}\right\} ; s\right)$ are modified to $U^{i}\left(\left\{X_{j, s}^{i}\right\} ; s\right)+\chi^{n}\left(B_{s}^{i}\left(\left\{X_{j, s}^{i}\right\}\right)\right.$ where $\chi^{n}$ is a sequence of smooth concave negative functions such that $\lim _{n \rightarrow \infty} \chi^{n}(x)=-\infty$ if $x>0$, and $\chi^{n}(x)=0$ if $x \leq 0$.

Consider the solution of the planning problem (5). We denote this solution for incomes and prices as $\bar{I}_{s}^{i}$ and $\bar{P}_{j, s}$, and we denote with bar variables any function evaluated at these income and prices. Suppose that the solution can be implemented with no financial taxes. This happens if and only if for all $i \in I, i^{\prime} \in I$ and for all $s \in S$ and $s^{\prime} \in S$,

$$
\frac{1-\sum_{j \in J_{s}} \bar{P}_{j, s} \bar{X}_{I, j, s}^{i^{\prime}} \bar{\tau}_{j, s}}{1-\sum_{j \in J_{s}} \bar{P}_{j, s} \bar{X}_{I, j, s}^{i} \bar{\tau}_{j, s}}=\frac{1-\sum_{j \in J_{s^{\prime}}} \bar{P}_{j, s^{\prime}} \bar{X}_{I, j, s^{\prime}}^{i^{\prime}} \bar{\tau}_{j, s^{\prime}}}{1-\sum_{j \in J_{s^{\prime}}} \bar{P}_{j, s^{\prime}} \bar{X}_{I, j, s^{\prime}}^{i} \bar{\tau}_{j, s^{\prime}}} .
$$

We introduce a perturbation of utility functions $U^{i, \epsilon}(\cdot ; s)$. We construct this perturbation such that the following properties are verified. First, the demand functions at the original incomes $\bar{I}_{s}^{i}$ and prices $\bar{P}_{j, s}$ are unchanged, i.e. for all $i \in I, j \in J$ and $s \in S$,

$$
\bar{X}_{j, s}^{i, \epsilon}=\bar{X}_{j, s}^{i}
$$

Second, the Slutsky matrices at the original incomes $\bar{I}_{s}^{i}$ and prices $\bar{P}_{j, s}$ are unchanged, i.e. for all $i \in I, j \in J$ and $s \in S$,

$$
\bar{S}_{k, j, s}^{i, \epsilon}=\bar{S}_{k, j, s}^{i}
$$

Third the income derivatives $X_{I, j, s}^{i, \epsilon}$ of the demand functions at the original incomes $\bar{I}_{s}^{i}$ and prices $\bar{P}_{j, s}$ are changed in such a way that for some $i \in I, i^{\prime} \in I$ and for all $s \in S$ and $s^{\prime} \in S$,

$$
\frac{1-\sum_{j \in J_{s}} \bar{p}_{j, s} \bar{X}_{I, j, s}^{i^{\prime}, \epsilon} \bar{\tau}_{j, s}}{1-\sum_{j \in J_{s}} \bar{P}_{j, s} \bar{X}_{I, j, s}^{i, \epsilon} \bar{\tau}_{j, s}} \neq \frac{1-\sum_{j \in J_{s^{\prime}}} \bar{P}_{j, s^{\prime}} \bar{X}_{I, j, s^{\prime}}^{i^{\prime}, \epsilon} \bar{\tau}_{j, s^{\prime}}}{1-\sum_{j \in J_{s^{\prime}}} \bar{P}_{j, s^{\prime}} \bar{X}_{I, j, s^{\prime}}^{i, \epsilon} \bar{\tau}_{j, s^{\prime}}} .
$$

Fourth, the marginal utilities of income at the original incomes $\bar{I}_{s}^{i}$ and prices $\bar{P}_{j, s}$ change in such a way the social marginal utilities of income are unchanged, i.e. for all $i \in I$, and $s \in S$,

$$
\frac{\lambda^{i} \bar{V}_{I, s}^{i, \epsilon}}{1-\sum_{j \in J_{s}} \bar{P}_{j, s} \bar{X}_{I, j, s}^{i, \epsilon} \bar{\tau}_{j, s}}=\frac{\lambda^{i} \bar{V}_{I, s}^{i}}{1-\sum_{j \in J_{s}} \bar{P}_{j, s} \bar{X}_{I, j, s}^{i} \bar{\tau}_{j, s}} .
$$

Taken together, these conditions guarantee the incomes $\bar{I}_{s}^{i}$ and prices $\bar{P}_{j, s}$ still solve the planning problem with the perturbed utility functions. Indeed, at these incomes and prices, and with the perturbed utility functions, the constraints are still verified (because the quantities demanded are unchanged), and so are the first order conditions for optimality because the Slutsky matrices and 
the social marginal utilities of income are unchanged. ${ }^{26,27,28}$ And given that (8) is violated, the solution cannot be implemented without financial taxes.

Since the original allocation is not first best by assumption, there exists a state $s \in S$ and a good $j \in J_{s}$ such that $\tau_{j, s} \neq 0$. Our proposed perturbation actually only changes utility for a single agent $i \in I$ this state state $s$. All the other utility functions are unchanged. We proceed by first determining income effects that change the optimal financial taxes. Assume that

$$
\bar{X}_{I, j, s}^{i, \epsilon}=\bar{X}_{I, j, s}^{i}+\epsilon Z_{j, s}^{i}
$$

for some vector $Z_{j, s}^{i}$ such that

$$
\sum_{j \in J_{s}} \bar{P}_{j, s} Z_{j, s}^{i} \bar{\tau}_{j, s} \neq 0
$$

Because they are income effects, and we want to retain the unperturbed prices, we must also have

$$
\sum_{j \in J_{s}} \bar{P}_{j, s} Z_{j, s}^{i}=0 .
$$

This is possible as long as there are at least two goods, and that there exists $j \in J_{s}$ such that $\tau_{j, s} \neq 0$ (recall that by construction $\tau_{j^{*}(s), s}=0$ ). To engineer such income effects while preserving the Slutsky matrix, we follow Geanakoplos and Polemarchakis (1980). We start with the problem of the agent:

$$
V^{i, \epsilon}\left(I_{s}^{i},\left\{P_{j, s}\right\}\right)=\max _{\left\{X_{j, s}^{i}\right\}} U^{i, \epsilon}\left(\left\{X_{j, s}^{i}\right\} ; s\right),
$$

subject to

\footnotetext{
${ }^{26}$ Because of the homogeneity of degree 0 in $I_{s}^{i}$ and $P_{s}$ of $V_{s}^{i}$ and $X_{j, s^{\prime}}^{i}$ there might be an issue of indeterminacy leading to the solution of the planning problem not being locally unique. If that is the case, we expand the function $\Gamma$ to include a normalization of certain prices to rule out this indeterminacy without changing the allocations that solve the planning problem.

${ }^{27}$ Note that we can rewrite the planning problem as maximizing $\sum_{i \in I} \sum_{s \in S} \lambda^{i} U^{i}\left(\left\{X_{j, s}^{i}\right\} ; s\right)$ subject to the resource constraints that $F\left(\left\{\sum_{i \in I} X_{j, s}^{i}\right\}\right) \leq 0$, the price constraint that $\Gamma\left(\left\{P_{j, s}\right\}\right) \leq 0$, and the first order conditions of the agents that for all $i \in I, s \in S, j \in J_{s}$ and $j^{\prime} \in J_{s}, U_{j}^{i}\left(\left\{X_{j, s}^{i}\right\} ; s\right) / P_{j, s}=U_{j^{\prime}}^{i}\left(\left\{X_{j, s}^{i}\right\} ; s\right) / P_{j^{\prime}, s}$. We we assume, as is generically the case, that the second order conditions of this planning problem are strictly satisfied on the manifold of allocations that satisfy the constraints.

${ }^{28}$ Our perturbations $U^{i, \epsilon}\left(\left\{X_{j, s}^{i}\right\} ; s\right)=\alpha_{s}^{i} U^{i}\left(\left\{X_{j, s}^{i}\right\} ; s\right)+\frac{\epsilon}{2}\left(X_{s}^{i}\right)^{\prime} \Omega_{s}^{i} X_{s}^{i}-\epsilon\left(\bar{X}_{s}^{i}\right)^{\prime} \Omega_{s}^{i} X_{s}^{i}$, which add linear and quadratic terms scaled by $\epsilon$ to the utility functions $U^{i}(\cdot ; s)$, are such that for $\epsilon$ small enough, the incomes $\bar{I}_{s}^{i}$ and prices $\bar{P}_{j, s}$ are a global maximum of the non-perturbed planning problem, but may only be a local maximum of the perturbed planning problem. We can always modify the perturbations so they are also a global maximum of the perturbed planning problem by adding $\epsilon \chi_{O_{s}^{i}}^{n}(\cdot ; s)$ to $U^{i, \epsilon}(\cdot ; s)$ for well chosen convex bounded neighborhoods $O_{s}^{i}$ of $\bar{X}_{s}^{i}$ and some large enough value of $n$, where $\chi_{O_{s}^{i}}^{n}$ is a sequence of smooth concave negative functions such that: if $\left\{X_{j, s}^{i}\right\} \in O_{s}^{i}$, then $\chi_{O_{s}^{i}}^{n}\left(\left\{X_{j, s}^{i}\right\} ; s\right)=0$; if $\left\{X_{j, s}^{i}\right\} \notin O_{s}^{i}$ then $\lim _{n \rightarrow \infty} \chi_{O_{s}^{i}}^{n}\left(\left\{X_{j, s}^{i}\right\} ; s\right)=-\infty$ uniformly on compact subsets of the complement $\left(\bar{O}_{s}^{i}\right)^{c}$ of the closure $\bar{O}_{s}^{i}$ of $O_{s}^{i}$; and for all $K>0$, there exists a compact set $O_{s}^{i, K} \supset O_{s}^{i}$ such that for all $n$, if $\left\{X_{j, s}^{i}\right\} \notin O_{s}^{i, K}$, then $\chi_{O_{s}^{i}}^{n}\left(\left\{X_{j, s}^{i}\right\} ; s\right)+\frac{1}{2}\left(X_{s}^{i}\right)^{\prime} \Omega_{s}^{i} X_{s}^{i}-\left(\bar{X}_{s}^{i}\right)^{\prime} \Omega_{s}^{i} X_{s}^{i}<-K$.
} 


$$
\sum_{j \in J_{s}} P_{j, s} X_{j, s}^{i} \leq I_{s}^{i}
$$

The first order condition, in vector notation, is

$$
D U_{s}^{i, \epsilon}-\omega_{s}^{i} P_{s}=0,
$$

where $\omega_{s}^{i}$ is the multiplier on the budget constraint. By the envelope theorem,

$$
\omega_{s}^{i}=V_{I, s^{\prime}}^{i, \epsilon}
$$

and by non-satiation,

$$
\sum_{j \in J_{s}} P_{j, s} X_{j, s}^{i}=I_{s}^{i}
$$

Holding income constant, totally differentiating, and evaluating the derivatives at incomes $\bar{I}_{s}^{i}$ and prices $\bar{P}_{j, s}$,

$$
D^{2} \bar{U}_{s}^{i, \epsilon} D \bar{X}_{s}^{i, \epsilon}-\bar{V}_{I, s}^{i, \epsilon} d P_{s}-\bar{P}_{s} \otimes D \bar{V}_{I, s}^{i, \epsilon}=0,
$$

and

$$
\left(\bar{X}_{s}^{i, \epsilon}\right)^{\prime} d P_{s}+\bar{P}_{s}^{\prime} D \bar{X}_{s}^{i, \epsilon}=0 .
$$

In block matrix form, these equations can be written as

$$
\left[\begin{array}{cc}
D^{2} \bar{U}_{s}^{i, \epsilon} & -\bar{P}_{s} \\
-\bar{P}_{s}^{\prime} & 0
\end{array}\right]\left[\begin{array}{c}
D \bar{X}_{s}^{i, \epsilon} \\
D \bar{V}_{I, s}^{i, \epsilon}
\end{array}\right]=\left[\begin{array}{c}
\bar{V}_{I, s}^{i, \epsilon} I \\
\left(\bar{X}_{s}^{i, \epsilon}\right)^{\prime}
\end{array}\right] d P_{s} .
$$

Geanakoplos and Polemarchakis (1980) show that the concavity of the utility function is sufficient to establish the invertibility of

$$
\left[\begin{array}{cc}
D^{2} \bar{U}_{s}^{i, \epsilon} & -\bar{P}_{s} \\
-\bar{P}_{s}^{\prime} & 0
\end{array}\right] .
$$

We construct the perturbation starting with the inverse matrix

$$
\left[\begin{array}{cc}
K^{\epsilon} & -v^{\epsilon} \\
-\left(v^{\epsilon}\right)^{\prime} & e^{\epsilon}
\end{array}\right]=\left[\begin{array}{cc}
D^{2} \bar{U}_{s}^{i, \epsilon} & -\bar{P}_{\mathcal{S}} \\
-\bar{P}_{s}^{\prime} & 0
\end{array}\right]^{-1},
$$

which implies that

$$
\left[\begin{array}{c}
D \bar{X}_{s}^{i, \epsilon} \\
D \bar{V}_{I, s}^{i, \epsilon}
\end{array}\right]=\left[\begin{array}{cc}
K^{\epsilon} & -v^{\epsilon} \\
-\left(v^{\epsilon}\right)^{\prime} & e^{\epsilon}
\end{array}\right]\left[\begin{array}{c}
\bar{V}_{I, s}^{i, \epsilon} I \\
\left(\bar{X}_{s}^{i, \epsilon}\right)^{\prime}
\end{array}\right] d P_{S}
$$


We choose

$$
K^{\epsilon}=\left(\bar{V}_{I, S}^{i, \epsilon}\right)^{-1} \bar{S}_{S}^{i}
$$

and

$$
v^{\epsilon}=\bar{X}_{I, s^{\prime}}^{i, \epsilon}
$$

so that the first equation of (67) is simply the Slutsky equation. We conclude that, in order to create the desired income effects while preserving the Slutsky matrix, it is necessary and sufficient to ensure that

$$
\left(\bar{V}_{I, s}^{i, \epsilon}\right)^{-1} \bar{S}_{s}^{i} D^{2} \bar{U}_{s}^{i, \epsilon}+\bar{X}_{I, S}^{i, \epsilon} \bar{P}_{s}^{\prime}=I
$$

and

$$
-\left(\bar{X}_{I, s}^{i, \epsilon}\right)^{\prime} D^{2} \bar{U}_{s}^{i, \epsilon}-e^{\epsilon} \bar{P}_{s}^{\prime}=0 .
$$

These two equations are sufficient for the perturbation to generate the desired income effects while preserving the Slutsky matrix. Because the equations hold for the unperturbed utility function and corresponding income effects, we can write

$$
\bar{S}_{S}^{i}\left(\left(\bar{V}_{I, S}^{i, \epsilon}\right)^{-1} D^{2} \bar{U}_{s}^{i, \epsilon}-\left(\bar{V}_{I, S}^{i}\right)^{-1} D^{2} \bar{U}_{s}^{i}\right)+\epsilon \bar{Z}_{I, S}^{i} \bar{P}_{s}^{\prime}=0,
$$

and

$$
\bar{Z}_{I, s}^{i}\left(D^{2} \bar{U}_{s}^{i, \epsilon}-D^{2} \bar{U}_{s}^{i}\right)=\left(e^{\epsilon}-e\right) \bar{P}_{s}^{\prime} .
$$

Now, we construct a utility function that preserves the demand at the incomes $\bar{I}_{s}^{i}$ and prices $\bar{P}_{j, s}$ while satisfying these equations (68) and (69) (so that the Slutsky matrix is unchanged and the desired income effects are produced), and preserving the social marginal utility of income. Define

$$
U^{i, \epsilon}\left(\left\{X_{j, s}^{i}\right\} ; s\right)=\alpha_{s}^{i} U^{i}\left(\left\{X_{j, s}^{i}\right\} ; s\right)+\frac{\epsilon}{2}\left(X_{s}^{i}\right)^{\prime} \Omega_{s}^{i} X_{s}^{i}-\epsilon\left(\bar{X}_{s}^{i}\right)^{\prime} \Omega_{s}^{i} X_{s}^{i}
$$

where $\Omega_{s}^{i}$ is a matrix and $\alpha_{s}^{i}$ is a scalar. First, note that

$$
D \bar{U}_{s}^{i, \epsilon}=\alpha_{s}^{i} D \bar{U}_{s}^{i}=\omega_{s}^{i, \epsilon} \bar{P}_{s}=\alpha_{s}^{i} \omega_{s}^{i} \bar{P}_{s}
$$

Therefore, at the incomes $\bar{I}_{s}^{i}$ and prices $\bar{P}_{j, s}$, the demand is unchanged. Applying the envelope theorem,

$$
\bar{V}_{I, S}^{i, \epsilon}=\alpha_{S}^{i} \bar{V}_{I, S}^{i} .
$$


To preserve the social marginal utility of income, we set

$$
\alpha_{s}^{i}=\frac{1-\sum_{j \in J_{s}} \bar{P}_{j, s} \bar{X}_{I, j, s}^{i, \epsilon} \bar{\tau}_{j, s}}{1-\sum_{j \in J_{s}} \bar{P}_{j, s} \bar{X}_{I, j, s}^{i} \bar{\tau}_{j, s}} .
$$

Note that

$$
D^{2} \bar{U}_{s}^{i, \epsilon}=\alpha_{s}^{i} D^{2} \bar{U}_{s}^{i}+\epsilon \Omega_{s}^{i} .
$$

Plugging this into (68), we must choose an $\Omega_{s}^{i}$ such that

$$
\left(\bar{V}_{I, s}^{i, \epsilon}\right)^{-1} \bar{S}_{S}^{i} \Omega_{s}^{i}+\bar{Z}_{I, S}^{i} \bar{P}_{s}^{\prime}=0 .
$$

Because the Slutsky matrix is a square symmetric matrix, we can write

$$
\bar{S}_{s}^{i}=\Sigma_{s}^{i} D_{s}^{i}\left(\Sigma_{s}^{i}\right)^{\prime},
$$

where $\Sigma_{s}^{i}$ has orthogonal rows and $D_{s}^{i}$ is diagonal. Suppose that, for some vector $\xi_{s}^{i}$

$$
\Omega_{s}^{i}=\Sigma_{s}^{i} \xi_{s}^{i} \bar{P}_{s}^{\prime}
$$

Then

$$
\bar{S}_{s}^{i} \Omega_{s}^{i}=\Sigma_{s}^{i} D_{s}^{i}\left(\Sigma_{s}^{i}\right)^{\prime} \Sigma_{s}^{i} \xi_{s}^{i} \bar{P}_{s}^{\prime}=\Sigma_{s}^{i} D_{s}^{i} \xi_{s}^{i} \bar{P}_{s}^{\prime} .
$$

We can solve for $\xi_{s}^{i}$ to satisfy the necessary equation,

$$
\xi_{s}^{i}=\bar{V}_{I, S}^{i, \epsilon}\left(D_{s}^{i}\right)^{+}\left(\Sigma_{s}^{i}\right)^{-1} \bar{Z}_{I, s}^{i}
$$

where $\left(D_{s}^{i}\right)^{+}$denotes the pseudo-inverse of $D_{s}^{i}$. This is possible because the non-zero eigenvectors of the Slutsky matrix form a basis for all vectors orthogonal to $\bar{P}_{S}$, and by assumption $\bar{Z}_{I, S}^{i}$ lies in this space. Finally, we can choose some $e^{\epsilon}$ scalar to satisfy (69).

\section{References}

Bianchi, Javier, "Overborrowing and Systemic Externalities in the Business Cycle," American Economic Review, December 2011, 101 (7), 3400-3426.

- and Enrique G. Mendoza, "Overborrowing, Financial Crises and 'Macro-prudential' Taxes," NBER Working Paper 16091 June 2010.

Blanchard, Olivier Jean and Nobuhiro Kiyotaki, "Monopolistic Competition and the Effects of Aggregate Demand," American Economic Review, September 1987, 77 (4), 647-66. 
Caballero, Ricardo J. and Arvind Krishnamurthy, "International and domestic collateral constraints in a model of emerging market crises," Journal of Monetary Economics, December 2001, 48 (3), 513-548.

Chari, V V and Patrick J Kehoe, "Sustainable Plans," Journal of Political Economy, August 1990, 98 (4), 783-802.

Correia, Isabel, Emmanuel Farhi, Juan Pablo Nicolini, and Pedro Teles, "Unconventional Fiscal Policy at the Zero Bound," American Economic Review, June 2013, 103 (4), 1172-1211.

_, Juan Pablo Nicolini, and Pedro Teles, "Optimal Fiscal and Monetary Policy: Equivalence Results," Journal of Political Economy, 02 2008, 116 (1), 141-170.

Davilla, Eduardo, “Dissecting Fire Sales Externalities,” Working Paper, Harvard August 2011.

Diamond, Peter A and James A Mirrlees, "Optimal Taxation and Public Production: IProduction Efficiency," American Economic Review, March 1971, 61 (1), 8-27.

Eggertsson, Gauti B. and Paul Krugman, "Debt, Deleveraging, and the Liquidity Trap: A FisherMinsky-Koo Approach," The Quarterly Journal of Economics, 2012, 127 (3), 1469-1513.

Farhi, Emmanuel and Ivan Werning, "Dealing with the Trilemma: Optimal Capital Controls with Fixed Exchange Rates," NBER Working Papers 18199, National Bureau of Economic Research, Inc June 2012.

_ and _ , "Fiscal Unions," NBER Working Papers 18280, National Bureau of Economic Research, Inc June 2012.

_ , Gita Gopinath, and Oleg Itskhoki, “Fiscal Devaluations," Technical Report 22014.

_, Mikhail Golosov, and Aleh Tsyvinski, "A Theory of Liquidity and Regulation of Financial Intermediation," Technical Report 32009.

Friedman, Milton, "The Case for Flexible Exchange Rates," in "Essays in Positive Economics," University of Chicago Press, 1953, pp. 157-203.

Geanakoplos, J D and H M Polemarchakis, "On the Disaggregation of Excess Demand Functions," Econometrica, March 1980, 48 (2), 315-31.

Geanakoplos, J., M. Magill, M. Quinzii, and J. Dreze, "Generic inefficiency of stock market equilibrium when markets are incomplete," Journal of Mathematical Economics, 1990, 19 (1-2), 113-151. 
Geanakoplos, John and Heracles M. Polemarchakis, "Existence, Regularity, and Constrained Suboptimality of Competitive Allocations When the Asset Market Is Incomplete," Cowles Foundation Discussion Papers 764, Cowles Foundation, Yale University 1985. available at http://ideas.repec.org/p/cwl/cwldpp/764.html.

Greenwald, Bruce C and Joseph E Stiglitz, "Externalities in Economies with Imperfect Information and Incomplete Markets," The Quarterly Journal of Economics, May 1986, 101 (2), 229-64.

Guerrieri, Veronica and Guido Lorenzoni, "Credit Crises, Precautionary Savings, and the Liquidity Trap," Working Paper 17583, National Bureau of Economic Research November 2011.

Hart, Oliver D., "On the optimality of equilibrium when the market structure is incomplete," Journal of Economic Theory, December 1975, 11 (3), 418-443.

Herings, P. and Herakles Polemarchakis, "Pareto improving price regulation when the asset market is incomplete," Economic Theory, 01 2005, 25 (1), 135-154.

Jeanne, Olivier and Anton Korinek, "Excessive Volatility in Capital Flows: A Pigouvian Taxation Approach," American Economic Review, May 2010, 100 (2), 403-407.

_ and _, "Macroprudential Regulation Versus Mopping Up After the Crash," NBER Working Papers 18675, National Bureau of Economic Research, Inc January 2013.

Kiyotaki, Nobuhiro and John Moore, "Credit Cycles," Journal of Political Economy, April 1997, 105 (2), 211-48.

Korinek, Anton, "The New Economics of Prudential Capital Controls: A Research Agenda," IMF Economic Review, August 2011, 59 (3), 523-561.

_ , "Capital Controls and Currency Wars," 2012. Mimeo, University of Maryland.

_ , "Systemic Risk: Amplification Effects, Externalities, and Regulatory Responses," Working Paper 2012.

_ and Alp Simsek, "Liquidity Trap and Excessive Leverage," NBER Working Papers 19970, National Bureau of Economic Research, Inc 2014.

Lorenzoni, Guido, “Inefficient Credit Booms," Review of Economic Studies, 2008, 75 (3), 809-833.

Lucas, Robert E., Jr. and Nancy L. Stokey, "Optimal Fiscal and Monetary Policy in an Economy without Capital," Journal of Monetary Economics, 1983, 12, 55-93.

Schmitt-Grohe, Stephanie and Martin Uribe, "Prudential Policies for Peggers," NBER Working Papers 18031, National Bureau of Economic Research, Inc June 2012.

Stein, Jeremy C., "Monetary Policy as Financial-Stability Regulation,” Technical Report 12012. 
Stiglitz, Joseph E, "The Inefficiency of the Stock Market Equilibrium," Review of Economic Studies, April 1982, 49 (2), 241-61.

Woodford, Michael, Interest and Prices: Foundations of a Theory of Monetary Policy, Princeton University Press, 2003.

_ , “Monetary Policy and Financial Stability,” Working Paper, Columbia University 2011. 